Article

\title{
Separators for Li-Ion and Li-Metal Battery Including Ionic Liquid Based Electrolytes Based on the TFSI $^{-}$and FSI $^{-}$Anions
}

\author{
Marija Kirchhöfer ${ }^{1}$, Jan von Zamory ${ }^{1}$, Elie Paillard ${ }^{1, *}$ and Stefano Passerini ${ }^{1,2, *}$ \\ 1 Institute of Physical Chemistry, University of Muenster, Corrensstraße 28-30, \\ Muenster 48149, Germany; E-Mails: marija.kirchhoefer@uni-muenster.de (M.K.); \\ jan.vonzamory@uni-muenster.de (J.Z.) \\ 2 Helmholtz Institute Ulm, Electrochemical Energy Storage, Albert-Einstein-Allee 11, 89081 Ulm, \\ Germany and Karlsruhe Institute of Technology PO Box 3640, Karlsruhe 76021, Germany \\ * Authors to whom correspondence should be addressed; \\ E-Mails: elie.paillard@uni-muenster.de (E.P.); stefano.passerini@kit.edu (S.P.); \\ Tel.: +49-73-1503-4101 (S.P.); Fax: +49-73-1503-4199 (S.P.).
}

Received: 24 May 2014; in revised form: 27 June 2014 / Accepted: 8 July 2014 /

Published: 22 August 2014

\begin{abstract}
The characterization of separators for Li-ion or Li-metal batteries incorporating hydrophobic ionic liquid electrolytes is reported herein. Ionic liquids made of $N$-butyl- $N$ methylpyrrolidinium $\left(\mathrm{PYR}_{14}{ }^{+}\right)$or $N$-methoxyethyl- $N$-methylpyrrolidinium $\left(\mathrm{PYR}_{12 \mathrm{O}}{ }^{+}\right)$, paired with bis(trifluoromethanesulfonyl)imide (TFSI ${ }^{-}$) or bis(fluorosulfonyl)imide (FSI ${ }^{-}$) anions, were tested in combination with separators having different chemistries and morphologies in terms of wetting behavior, Gurley and McMullin number, as well as $\mathrm{Li} /($ Separator + Electrolyte) interfacial properties. It is shown that non-functionalized microporous polyolefin separators are poorly wetted by $\mathrm{FSI}^{-}$-based electrolytes (contrary to $\mathrm{TFSI}^{-}$-based electrolytes), while the ceramic coated separator Separion ${ }^{\circledR}$ allows good wetting with all electrolytes. Furthermore, by comparing the lithium solid electrolyte interphase (SEI) resistance evolution at open circuit and during cycling, depending on separator morphologies and chemistries, it is possible to propose a scale for SEI forming properties in the order: $\mathrm{PYR}_{1201} \mathrm{FSI}>\mathrm{PYR}_{14} \mathrm{FSI}>\mathrm{PYR}_{14} \mathrm{TFSI}>\mathrm{PYR}_{1201}$ TFSI. Finally, the impact the separator morphology is evidenced by the SEI resistance evolution and by comparing Li electrodes cycled using separators with two different morphologies.
\end{abstract}

Keywords: ionic liquids; lithium metal; separator; Li-ion 


\section{Introduction}

Even though the use of renewable resources, such as wind, solar and tidal energy has grown in the last years and is foreseen to allow providing most of the energy consumption by 2030 [1-3], most of our energy consumption still derives from fossil fuels. In fact, the decrease of this proportion would require an increase of stationary energy storage capabilities, as most renewable sources provide electricity in an intermittent way, incompatible with the electric network needs, as well as a switch to electric transportation. For both purposes, larger battery packs, as compared to portable electronics, are needed, raising larger safety concerns.

Indeed, if secondary Li-ion batteries offer among the highest energy densities, with values up to $800 \mathrm{Wh} \cdot \mathrm{L}^{-1}$ for the latest generation of 18,650 cells, they are based on a system which is not thermodynamically stable. Indeed, lithiated graphite, generally used as anode, is unstable toward most chemicals and its operation is made possible by the kinetic passivation of its surface by electrolyte degradation products, forming a protective layer commonly called "Solid Electrolyte Interphase" (SEI) [4] by analogy with Li metal [5]. At the same time, layered oxide cathodes typically used in Li-ion cells, such as $\mathrm{LiCoO}_{2}, \mathrm{LiNi}_{0.33} \mathrm{Mn}_{0.33} \mathrm{Co}_{0.33} \mathrm{O}_{2}$ or $\mathrm{LiNiO}_{2}$, are known to release oxygen in case of overcharge or overheating $[6,7]$.

In addition, the electrolytes are made of a mixture of cyclic alkyl carbonates, usually ethylene carbonate (EC), and volatile linear alkyl carbonates with low flash points such as dimethyl carbonate $\left(\mathrm{T}_{\mathrm{F}(\mathrm{DMC})}=17{ }^{\circ} \mathrm{C}\right)$ or diethyl carbonate $\left(\mathrm{T}_{\mathrm{F}(\mathrm{DEC})}=25^{\circ} \mathrm{C}\right)$ and the use of the low thermal stability $[8,9]$ salt $\mathrm{LiPF}_{6}$ brings the additional concern of generating $\mathrm{HF}$ in case of contact with the atmosphere or water traces above $60{ }^{\circ} \mathrm{C}[10,11]$. For all these reasons, the operation of Li-ion batteries above $50{ }^{\circ} \mathrm{C}$ is problematic, especially as high temperatures can induce the failure of the SEI this resulting in the direct exothermic reaction of lithiated graphite with the electrolyte [12], possibly chain reactions, releasing rapidly the stored energy in what is generally referred to as "thermal runaway".

On the other hand, ionic liquids (ILs) have attracted a growing attention as electrolytes for Li-based batteries, due to their non-flammability, negligible vapor pressure, high thermal and electrochemical stabilities [13-17]. Indeed, if the use of graphite requires, for most IL-based electrolytes, the addition of additives, such as VC, for forming the SEI [18,19], some ILs based on the bis(fluorosulfonyl)imide (FSI) anion possess intrinsic SEI forming properties [20-23], as well as higher conductivities [20,24-26] as compared to the more commonly used bis(trifluoromethanesulfonyl)imide (TFSI ${ }^{-}$) based ILs. These electrolytes, in addition to allowing higher operation temperatures for Li-ion batteries, and thus easier heat management for large packs, also allow good reversibility of the $\mathrm{Li}$ metal electrode both for $\mathrm{TFSI}^{-}$[27] and $\mathrm{FSI}^{-}$-based electrolytes [26,28], which enables their use in emerging Li-metal battery technologies, such as Li-metal oxide, Li-air, and Li-S [17].

Besides the electrolyte, the separator plays an important safety role in lithium batteries by preventing the physical contact between the electrodes, while allowing the $\mathrm{Li}^{+}$ions transport through its pores, filled with the electrolyte. Tri-layered polyolefin separators including a polyethylene (PE) layer sandwiched between two polypropylene (PP) layers are commonly used in Li-ion batteries due to their chemical inertia and to the safety feature they offer, the so-called "shut-down effect" as, in case of overheating, the PE layer melts, loosing its porosity (i.e., mechanically blocking the $\mathrm{Li}^{+}$ion movement), while the PP layer prevents large dimensional changes until its own melting, 
thus preventing short-circuits [29-32]. Nevertheless, these separators still suffer from rather limited temperature range, with an onset for shrinkage around $100{ }^{\circ} \mathrm{C}$ [32]. Thus, in recent years, separators with "zero shrinkage", made of polymer coated with inorganic particles have been introduced, such as Separion $^{\circledR}$, allowing higher safety [33]. As Li-ion electrolytes are hydrophilic, these separators also allow for a better wetting as compared with polyolefin separators, which makes them especially suitable for large battery cells. Other materials, chemically less inert, such as cellulose have also been investigated [34,35] as cheaper alternatives to dry-stretched or wet processed commercial Li-ion separators.

However, in most reports on ionic liquids for Li-ion or Li-metal batteries, glass fiber (GF) separators are used, while their thickness of $c a .300 \mu \mathrm{m}$, versus ca. $25 \mu \mathrm{m}$ for commercial separators is not adapted for commercial applications. If the ionic liquid family is wide, the most promising ILs comprise the $\mathrm{TFSI}^{-}$and $\mathrm{FSI}^{-}$anions, which confer them hydrophobic properties, which a priori, makes them more compatible with polyolefin separators as compared with hydrophilic conventional electrolytes, even though their higher viscosity, raises questions. Nevertheless, no study can be found concerning the use of separators for IL-based electrolytes in Li-ion or Li-metal batteries.

If for Li-ion batteries the contact between the porous electrodes and the separator is limited to a small fraction of the tridimensional composite electrode total surface, which limits the interfacial reactivity, a different situation occurs in Li-metal batteries as the separator is in contact with a larger fraction of the total electrode surface, making the study of the interfacial reactivity more crucial. Indeed, the pre-existing "native" SEI, originating from the passivation of Li in dry air, might crack at the contact with the separator, as it is the case for semi-crystalline solid polymer electrolytes [36], which induces increased reactivity and electrolyte consumption for SEI "self-repair". Moreover, the main drawback of the Li electrode is the deposition of $\mathrm{Li}$ under the form of dendrites, which prevented so far the successful commercialization of liquid electrolyte-based, Li-metal secondary batteries, while commercial Li-metal polymer batteries do not include any separator. The formation of dendrites is not only related to the total current density [37,38], but, also, presumably, to the local variation of current densities linked to inhomogeneities within the SEI [39], which could also originate from the presence of a separator. Thus, separator's morphology and chemical composition are both likely to influence the properties of the $\mathrm{Li} /$ (electrolyte + separator) interface.

In this work, we investigated combinations of four different hydrophobic IL-based electrolytes with eight separators in terms of wettability, conductivity and behavior versus Li metal. Two commercial polyolefin microporous separators $\left(\right.$ Celgard $\left.^{\circledR}\right)$, as well as a ceramic-coated membrane (Separion ${ }^{\circledR}$ ), were used. In addition, polyamide and cellulose-based separators were tested in order to investigate the effect of the chemistry on the ensemble (separator + electrolyte). For comparison, high porosity separators (non woven mats) including two glass fiber separators, as well as a PP separator, were also investigated.

\section{Results and Discussion}

\subsection{Separator Characterization}

Figure 1 shows the SEM images of the separators, which basic properties are reported in Table 1. The Celgard ${ }^{\circledR}$ microporous polyolefin separators (Figure 1a,b) exhibit typical dry-streched morphologies, 
where the pore size of the monolayer separator $\operatorname{Celgard}^{\circledR} 2500$ is larger than that of the outer layer of Celgard ${ }^{\circledR} 2325$. The scanning electron microscopy (SEM) image of FS2190, shown in Figure 1c, reveals large fibers of $c a .10 \mu \mathrm{m}$ diameter. In Figure 1d, it can be seen that the polyamide membrane has a tridimensional porous structure, probably originating from a wet processing. The cellulose "Copa Spacer" (Figure 1e) is constituted of non-woven fibers. Finally, only the inorganic outer layer of Separion ${ }^{\circledR}$ can be seen in Figure 1f.

Figure 1. Scanning electron microscopy (SEM) images of (a) Celgard $^{\circledR} 2325$ (PP/PE/PP); (b) Celgard ${ }^{\circledR} 2500$ (PP); (c) Freudenberg FS2190 (PP); (d) Polyamide; (e) Copa spacer (cellulose); and (f) Separion ${ }^{\circledR}$ (PET/ceramic).

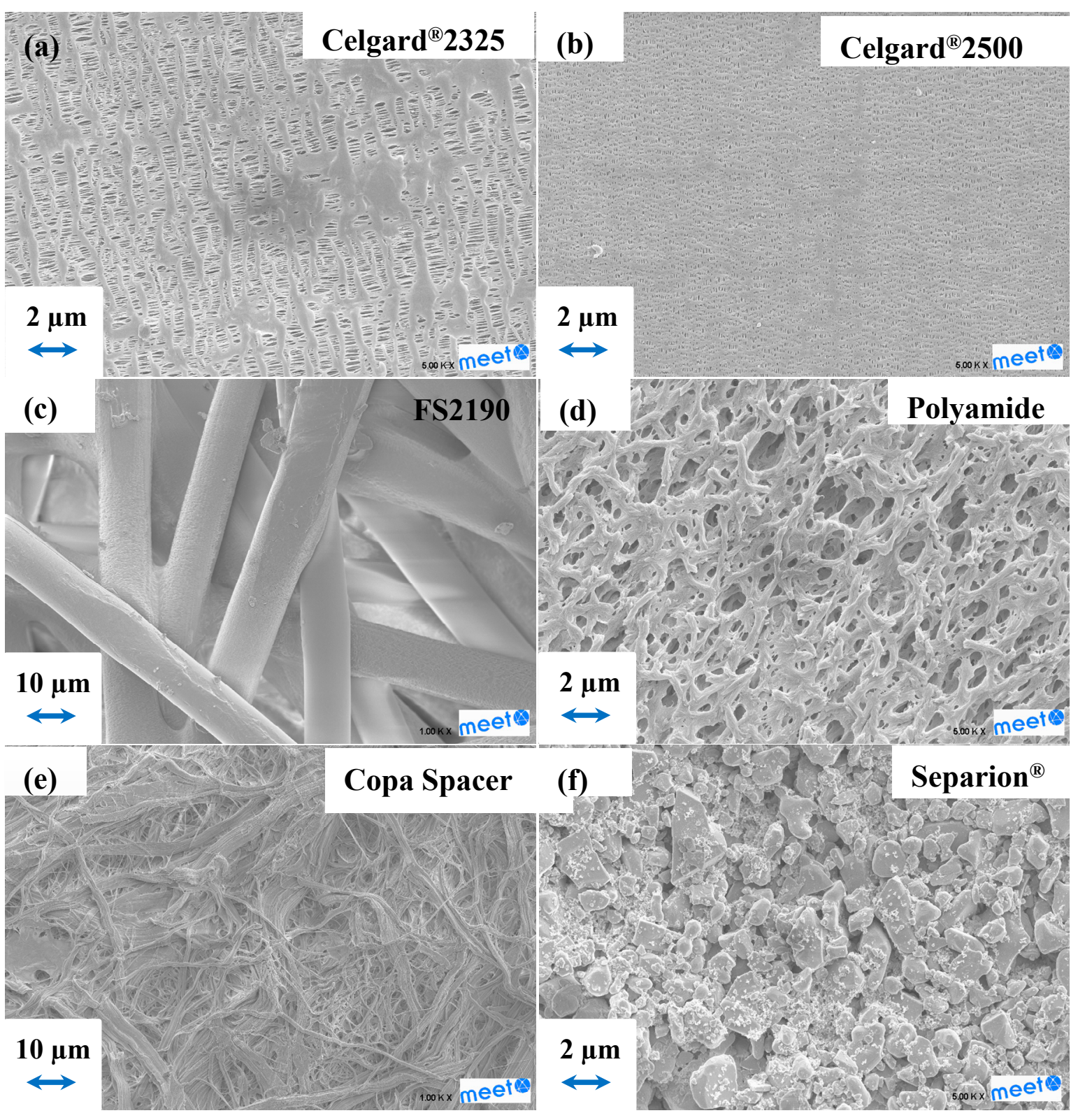

The Gurley numbers, (i.e., the time for $100 \mathrm{~cm}^{3}$ of air to flow through 1.0 square inch under a pressure difference of 12.96 mbar) of the various separators are listed in Table 1. The microporous polyolefin Celgard separators show lower air permeability than the other separators, which values are coherent with those from the supplier (Celgard ${ }^{\circledR} 2500$ : $200 \mathrm{~s}$; $\operatorname{Celgard}^{\circledR} 2325: 620 \mathrm{~s}$ ). The measurement 
was not possible for Freudenberg FS2190 due to its high permeability. Despite their thickness, Whatman ${ }^{\circledR} \mathrm{GF} / \mathrm{F}$ exhibits a Gurley number of $2.3 \mathrm{~s}$ and Whatman ${ }^{\circledR} \mathrm{GF} / \mathrm{C}$ of only $1.0 \mathrm{~s}$. The non-woven cellulose separator also shows a low permeability, while the ceramic coated separator Separion ${ }^{\circledR}$ and the polyamide membrane exhibit intermediate values.

Table 1. Composition, thickness and air permeability (Gurley numbers) of the separators.

\begin{tabular}{cccc}
\hline Separator & Composition & $\begin{array}{c}\text { Thickness } \\
(\boldsymbol{\mu m})\end{array}$ & $\begin{array}{c}\text { Gurley } \\
\text { Number }(\mathbf{s})\end{array}$ \\
\hline Celgard $^{\circledR} 2325$ (Polypore) & PP/PE/PP & 27 & 570.0 \\
Celgard $^{\mathbb{B}} 2500$ (Polypore) & PP & 27 & 180.1 \\
FS2190 (Freudenberg and Co.KG) & PP & 176 & - \\
Polyamide $0.2 \mu$ m (Sartotius Stedium Biotech GmbH) & Polyamide & 116 & 31.9 \\
Copa Spacer (Spez. Papierfabrik Oberschmitt GmbH) & Cellulose & 50 & 6.5 \\
Separion ${ }^{\circledR}($ Evonik) & Ceramic on PET & 28 & 22.8 \\
GF/C (Whatman) & Glass fiber & 283 & 1.0 \\
GF/F (Whatman) & Glass fiber & 359 & 2.3 \\
\hline
\end{tabular}

\subsection{Wetting of the Separators}

The wettability of a membrane depends on several factors, such as porosity and surface roughness and, for a given electrolyte, on its chemical affinity for the membrane material, as well as its viscosity. The evolutions of the contact angle of electrolyte drops deposited onto the separators are shown in Figure 2a-c, with the ensemble $\left(1 \mathrm{M} \mathrm{LiPF}_{6}, \mathrm{EC}: \mathrm{DMC}(1: 1)+\right.$ Celgard $\left.^{\circledR} 2325\right)$ reported in Figure 2a for comparison. For all electrolytes, the GF/C separator shows the fastest wetting (similarly to GF/F, not shown) as a result of its open porosity. FS2190, which possesses even higher air permeability, does not allow for as fast a wetting, showing that, even if the electrolytes are hydrophobic, they have a better affinity for the hydrophilic $\mathrm{SiO}_{2}$ surface than for that of polyolefin. This is especially obvious for the Celgard $^{\circledR}$ separators, which exhibit the slowest wetting performance, as a combined effect of poor surface affinity and low porosity. A major difference between $\mathrm{TFSI}^{-}$and $\mathrm{FSI}^{-}$is evidenced with these latter separators. If, for PYR ${ }_{14}$ TFSI and PYR 1201 TFSI, the contact angle slowly decreases with time (Figure 2a,c), similarly to the conventional and low viscosity electrolyte $1 \mathrm{M} \mathrm{LiPF}_{6}$ in EC:DMC (1:1), this is not the case for PYR ${ }_{14} \mathrm{FSI}$ and $\mathrm{PYR}_{1201} \mathrm{FSI}$ (Figure 2b,d), for which the contact angle remains remarkably constant. Despite their lower viscosities, FSI $^{-}$-based electrolytes show a poorer affinity with polyolefin separators, which could be linked to the lack of hydrophobic perfluorinated carbons in these ILs, despite their overall hydrophobicity. Although PYR ${ }_{14}$ TFSI and PYR ${ }_{1201}$ TFSI-based electrolytes are both able to slowly wet the Celgard ${ }^{\circledR}$ separators (Figures 2a,b), PYR ${ }_{14}$ TFSI exhibits lower contact angles and a much faster wetting, which can be related only to the lack of ether function in the side chains since its viscosity is higher [40]. The behavior toward the more hydrophilic separators are more difficult to interpret, however, a general scale of hydrophobicity, based on the wettability results of the three polyolefin separators can be proposed: $\mathrm{FSI}^{-}<\mathrm{TFSI}^{-}$and $\mathrm{PYR}_{1(2 \mathrm{O})}{ }^{+}<\mathrm{PYR}_{14}{ }^{+}$. 
Figure 2. Evolution of the contact angle of drops of $10 \mathrm{~mol} \%$ LiTFSI electrolytes deposited on the separators: (a) PYR 14 TFSI $\left(1 \mathrm{M} \mathrm{LiPF}_{6}\right.$ in EC:DMC $(1: 1)+$ Celgard $^{\circledR} 2325$ included for comparison); (b) PY ${ }_{14}$ FSI; (c) PYR ${ }_{1201}$ TFSI; and (d) PYR ${ }_{1201}$ FSI.
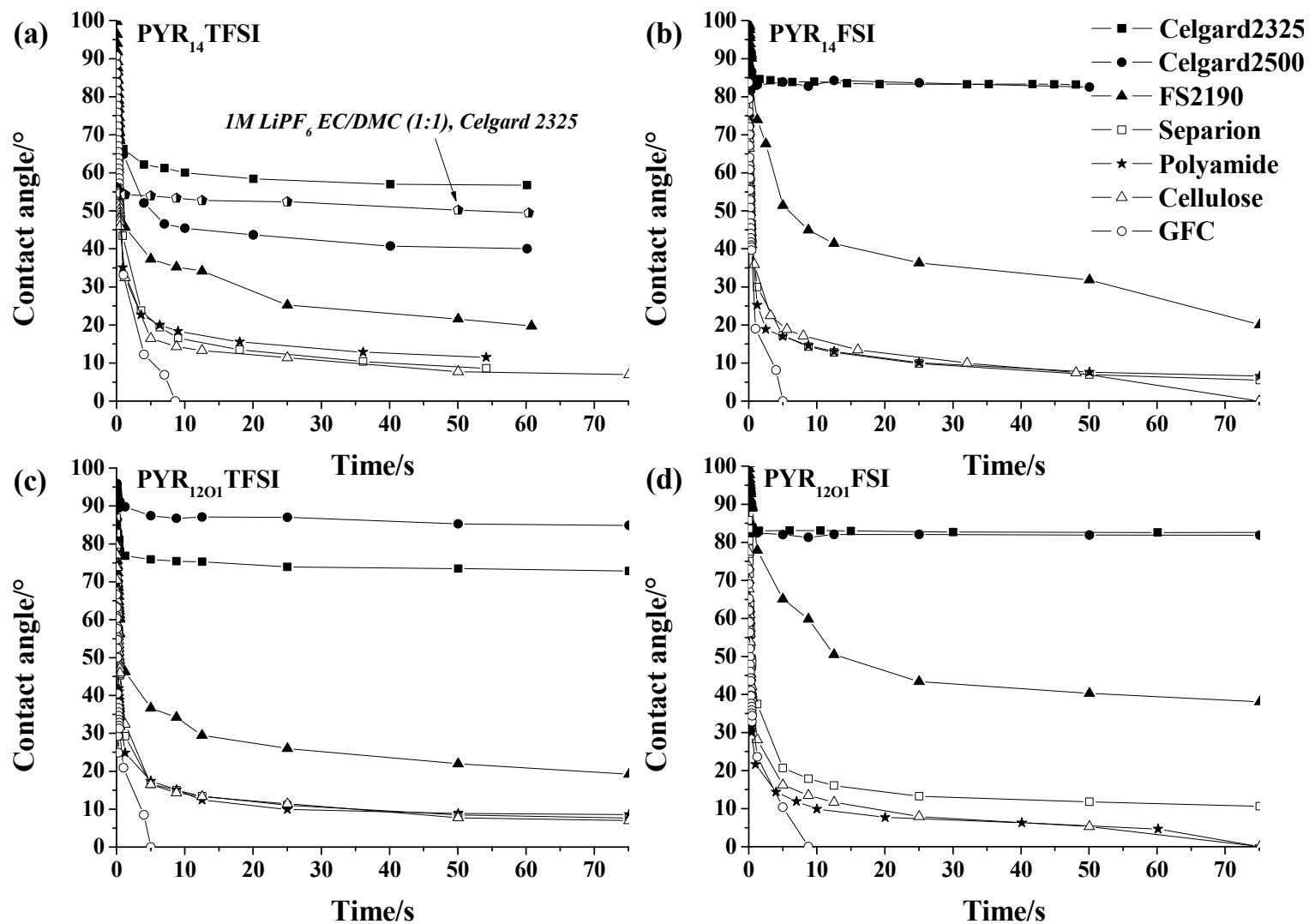

The more hydrophilic Separion ${ }^{\circledR}$ and the polyamide membrane showed in most cases similar trends and a good affinity with all electrolytes. The hydrophilic cellulose-based Copa Spacer showed a rapid decrease of contact angles and a complete absorption of $\mathrm{PYR}_{14}{ }^{+}$-based electrolytes within $80 \mathrm{~s}$, while $\mathrm{PYR}_{12 \mathrm{O} 1}{ }^{+}$electrolytes absorption was slightly slower.

Overall, the hydrophobicity of the ILs does not favor polyolefin separators in terms of wetting, although they can be wetted by TFSI-based electrolytes. Among the thin commercial separators tested, Separion ${ }^{\circledR}$, thanks to its hydrophilicity, allows for the fastest wetting.

\subsection{Influence of the Separator on the Conductivity}

The influence of the separator on the conductivity of the ensemble (electrolyte + separator) is reflected through its MacMullin number $\mathrm{Nm}$, the ratio of the resistivity of the combination (electrolyte + separator) alone by the resistivity of the electrolyte. It can be seen in Table 2 that the commercial separators including a safety feature (shut-down for Celgard ${ }^{\circledR} 2325$ and "zero shrinkage" for Separion ${ }^{\circledR}$ ) exhibit the highest $N \mathrm{~m}$, although in line with Li-ion requirements [33]. For Celgard ${ }^{\circledR} 2325$, only PYR ${ }_{14}$ TFSI:LiTFSI was able to wet the separator properly in the conditions of this study, which led to a Nm similar to that of conventional Li-ion (ca. 10) [33] while the values obtained with PYR $_{1201}$ TFSI probably result from a poor wetting as no vacuum was applied during the tests. Interestingly, Celgard ${ }^{\circledR} 2500$ combines well with PYR ${ }_{14}$ TFSI-based electrolytes, with a rather low $N \mathrm{~m}$ of 5, which makes it a good alternative to GF separators because its lower thickness makes it less 
detrimental to battery energy density and internal resistance. For $\mathrm{PYR}_{14} \mathrm{FSI}$-based electrolyte, Separion ${ }^{\circledR}$ is the best compromise between resistivity and thickness. Among the non-woven separators, Freudenberg FS2190 exhibits a $\mathrm{Nm}$ around 2-4 while the lowest $\mathrm{Nm}$ were measured for the GF separators, although it has to be pointed out that, if $\mathrm{SiO}_{2}$ has been reported to enhance conductivity in aprotic electrolytes [41-43] it could as well be an experimental artifact linked to the compressibility of these separators during the measurement of their $\mathrm{Nm}$.

Table 2. Calculated McMullin numbers ( $\mathrm{Nm})$ for $0.1 \mathrm{~mol} \%$ LiTFSI electrolytes.

\begin{tabular}{|c|c|c|c|c|}
\hline Separator & PYR $_{14}$ TFSI & PYR 1(201) TFSI & PYR $_{14}$ FSI & $\mathrm{PYR}_{1(2 \mathrm{O})} \mathrm{FSI}$ \\
\hline Celgard $^{\circledR} 2325$ & 11 & $27 *$ & 1 & 1 \\
\hline Celgard $^{\circledR} 2500$ & 5 & $36^{*}$ & / & I \\
\hline Freudenberg FS2190 & 3 & 4 & 2 & 3 \\
\hline Polyamide & 6 & 3 & 2 & 3 \\
\hline Copa Spacer & 3 & 4 & 3 & 4 \\
\hline Separion $^{\circledR}$ & 9 & 10 & 7 & 11 \\
\hline Whatman ${ }^{\circledR} \mathrm{GF} / \mathrm{C}$ & 1 & 1 & 1 & 1 \\
\hline Whatman ${ }^{\circledR} \mathrm{GF} / \mathrm{F}$ & 1 & 1 & 1 & 1 \\
\hline
\end{tabular}

* Probably resulting from incomplete wetting of the separator.

\subsection{Static Evolution of the Solid Electrolyte Interphase (SEI) Resistance}

The evolutions of the SEI resistances, at $21{ }^{\circ} \mathrm{C}$, in contact with the different combinations (electrolyte + separator), are shown in Figure 3. The $\mathrm{FSI}^{-}$-based ILs led to much lower resistances as compared with TFSI $^{-}$-based ILs. Among the separators, FS2190 led to the highest resistances, especially when compared to the other polyolefin separators, which can be attributed to the large diameter of its constituting fibers, more likely to induce important damage to the native SEI and subsequent repair [36] by contact. If it was not possible to measure SEI resistance in combination with FSI $^{-}$based electrolytes, due to their poor wetting, Celgard ${ }^{\circledR}$ membranes, overall, led to the lowest resistances for PYR $_{14}$ TFSI, probably due to their relatively high chemical inertia, combined with their low surface roughness as compared to FS2190. This latter allows comparing the electrolytes in combination with a low reactivity separator inducing a priori significant SEI cracking, which suggests that the effectiveness of the electrolytes for SEI building/repairing follows the order: $\mathrm{PYR}_{12 \mathrm{O} 1} \mathrm{FSI}>\mathrm{PYR}_{14} \mathrm{FSI}>\mathrm{PYR}_{14}$ TFSI $>\mathrm{PYR}_{12 \mathrm{O} 1}$ TFSI. This confirms the good SEI forming properties of $\mathrm{FSI}^{-}$while the higher reactivity of $\mathrm{PYR}_{12 \mathrm{Ol}}{ }^{+}$[40] seems to be effective only when combined with $\mathrm{FSI}^{-}$, PYR $12 \mathrm{O} 1$ TFSI exhibiting the worst behavior toward SEI building. However, the latter material shows comparable SEI resistance to those of PYR ${ }_{14}$ TFSI in the case of the GF, Celgard ${ }^{\circledR}$ and Separion ${ }^{\circledR}$ separators. 
Figure 3. Evolution of the SEI resistance of Li electrodes in contact with $10 \%$ mol LiTFSI electrolytes combined with different separators (a) PYR 14 TFSI; (b) PY 1201 TFSI; (c) PYR ${ }_{14}$ FSI; and (d) PYR $_{1201}$ FSI.

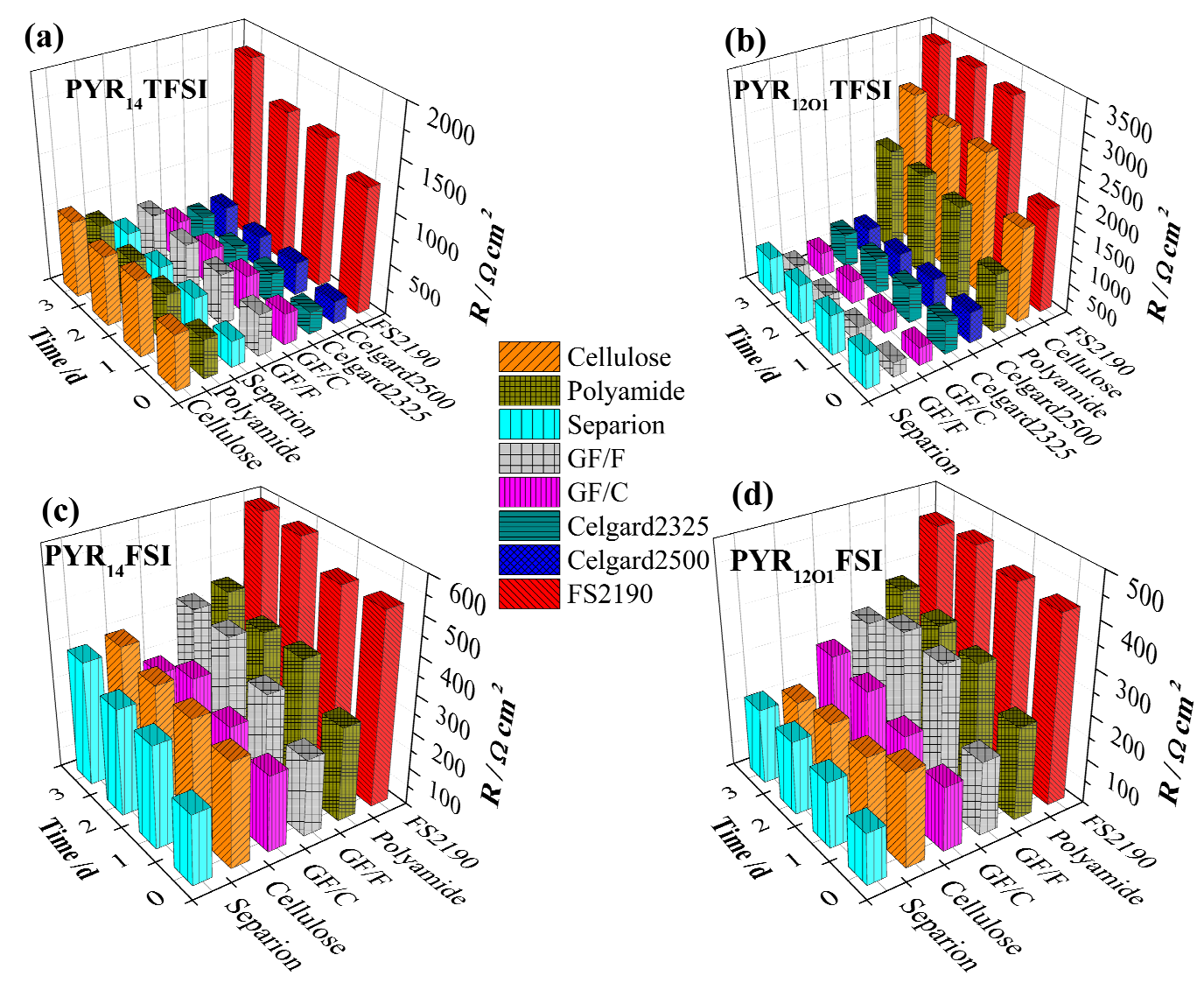

The cellulose separator led to comparatively high SEI resistances for TFSI-based electrolytes, whereas with $\mathrm{PYR}_{12 \mathrm{O}} \mathrm{FSI}$ and $\mathrm{PYR}_{14} \mathrm{FSI}$ the resulting resistances were among the lowest. It should be pointed out that the morphology of the separator has a greater influence than its chemistry as, if cellulose and polyamide lead to larger SEI resistances as compared to that of Celgard ${ }^{\circledR}$ separators, for the TFSI-based electrolytes (Figure 3a,b), their reactivity is compensated by the SEI building properties of the FSI-based electrolytes. The resulting SEI resistances (Figure 3c,d) are in the same range than those obtained with GF separators. In contrast, with the worst SEI forming electrolyte, $\mathrm{PYR}_{12 \mathrm{O} 1}$ TFSI, these are among the highest. In particular, for all electrolytes, the SEI resistances are lower than those measured for the more inert, but rougher, FS2190. The results obtained with these two reactive separators, however, confirm the relative efficiencies of the electrolytes concerning their SEI forming properties deduced from the polyolefin separators results. Separion ${ }^{\circledR}$ led to relatively low resistances in all cases, with, remarkably, among the lowest measured resistances for FSI-based ILs.

\subsection{Lithium Plating/Stripping Tests}

The symmetrical cells used for the SEI evolution study were then subjected to galvanostatic cycling at $0.1 \mathrm{~mA} \cdot \mathrm{cm}^{-2}$, reversing the polarity every hour, for 100 cycles at $40{ }^{\circ} \mathrm{C}$. These cells were periodically subjected to impedance measurements (at $21^{\circ} \mathrm{C}$ ) to follow the evolution of the electrolyte resistance and the SEI resistance. 


\subsubsection{Glass Fiber Separators}

GF separators allow extended cycling of lithium with both PYR ${ }_{14}$ TFSI [44] and $\mathrm{PYR}_{14} \mathrm{FSI}^{-}$based electrolytes [29,31]. For these separators, the voltage profiles, illustrated in Figure 4a,b, follow those typically linked to the extension of concentration gradients with time and neither steady-state potentials nor Sand time [45] are reached within one hour. If, for the thicker GF/F separator, the cell polarization is higher than for $\mathrm{GF} / \mathrm{C}$, we observe only minimal voltage evolution with cycling, showing that, for 100 cycles, neither SEI nor electrolyte are significantly modified. As seen in Figure 4c, the SEI resistance first increases and then slightly decreases. Rather similar values of SEI resistances are observed for the two GF separators, with variations from cell to cell and slightly lower values obtained, in general, with GF/C separators. The electrolyte resistance, corresponding to the high frequency intercept with the real axis showed in the insert of Figure $4 \mathrm{c}$,d, increases slightly over cycling, but always being small as compared to the SEI resistance (at $21^{\circ} \mathrm{C}$ ). Overall, the mass transport is more limiting than the resistance of the electrolyte and the influence of the SEI variations on the voltage profiles is minimal within the duration of the test. The effect of the separator thickness can be seen in the evolution of electrolyte resistances, with the thicker GF/F leading to almost no change while GF/C leads to limited electrolyte resistance increase, linked to the lower amount of electrolyte contained.

Figure 4. Evolution of $\mathrm{PYR}_{14}$ TFSI-based electrolyte cells during cycling at $40{ }^{\circ} \mathrm{C}$ and $0.1 \mathrm{~mA} \cdot \mathrm{cm}^{-2}$ (a) Voltage profiles of a $\mathrm{GF} / \mathrm{F}$ cell; (b) Voltage profile of a $\mathrm{GF} / \mathrm{C}$ cell; (c) Evolution of the impedance spectra at $21^{\circ} \mathrm{C}$ of a $\mathrm{GF} / \mathrm{F}$ cell; and (d) Evolution of the impedance spectra at $21^{\circ} \mathrm{C}$ of a GF/C cell.
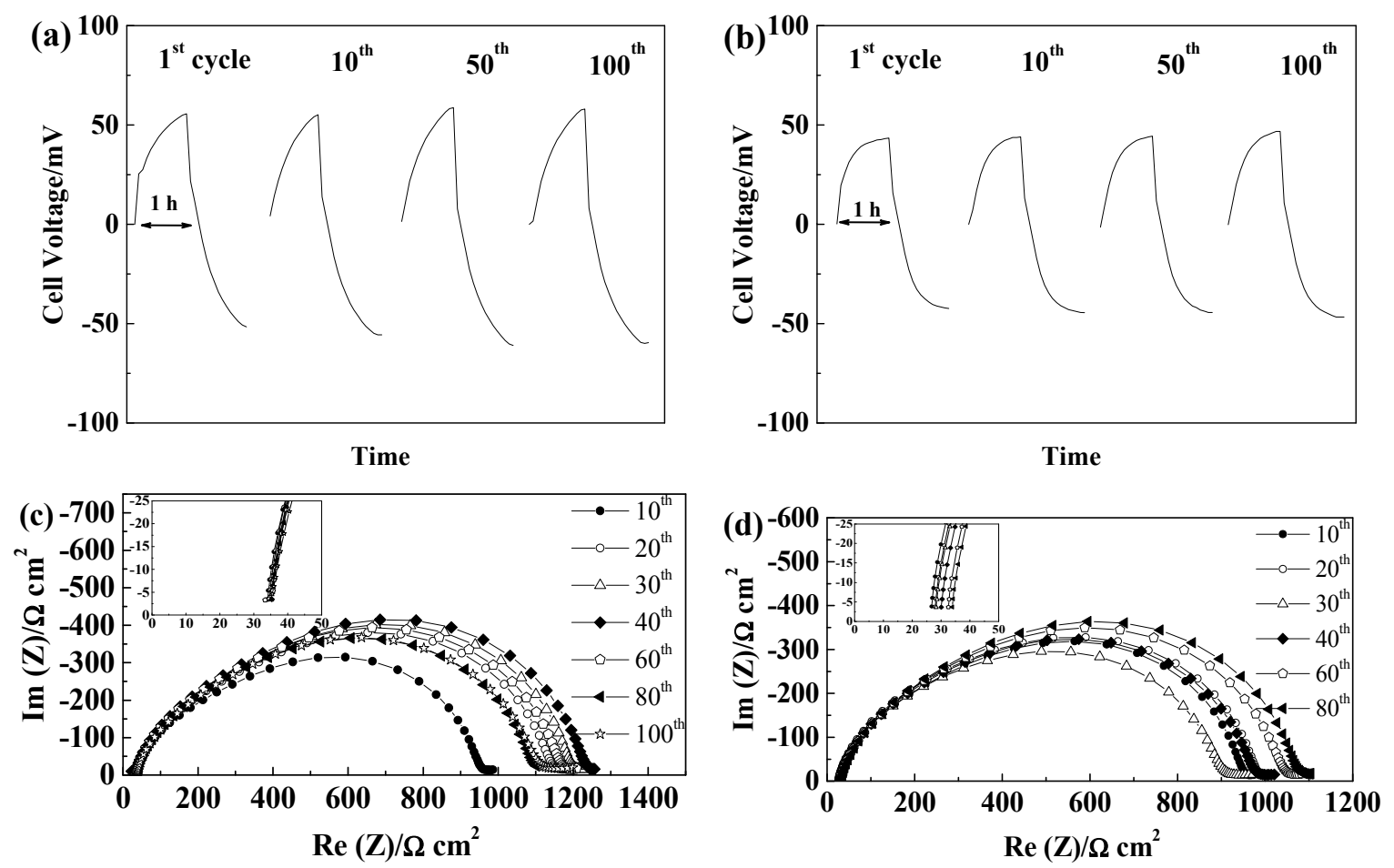
The PYR ${ }_{1201}$ TFSI-based electrolyte led to rather similar behavior, with stable end of cycle voltages around $40 \mathrm{mV}$ for $\mathrm{PYR}_{1201} \mathrm{TFSI} / \mathrm{GF} / \mathrm{C}$, as a result of a very stable and low resistance SEI, as seen in Figure 5a,b.

Figure 5. Evolution during cycling at $40^{\circ} \mathrm{C}$ and $0.1 \mathrm{~mA} \cdot \mathrm{cm}^{-2}$ of a $\mathrm{PYR}_{12 \mathrm{O} 1} \mathrm{TFSI}$-based cell incorporating a GF/C separator (a) Voltage profile of a GF/C cell; (b) Evolution of the impedance spectra at $21^{\circ} \mathrm{C}$ of the $\mathrm{GF} / \mathrm{C}$ cell shown in (a).
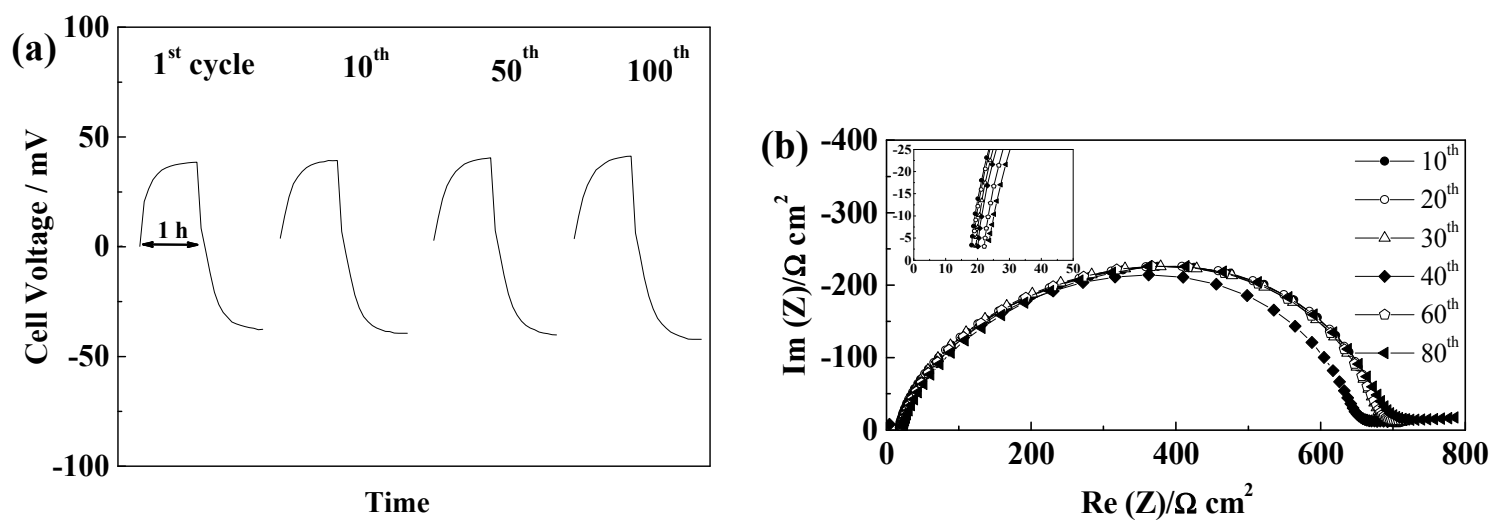

The $\mathrm{FSI}^{-}$-based electrolytes led to lower cell voltage as a result of the lower mass transport resistance of the electrolytes, resulting in low steady-state voltages reached rapidly, as illustrated in Figure 6 for $\mathrm{PYR}_{12 \mathrm{O} 1} \mathrm{FSI}$, with a slight increase followed by stabilization and cell voltages below $25 \mathrm{mV}$. The resistance of the electrolyte (see insert in Figure 6b) increases slightly over cycling, while the SEI resistance first increases prior to decreasing slightly above its starting value. The PYR ${ }_{14} \mathrm{FSI}$ based electrolyte led to slightly higher cell voltage (not shown) around $0.3-0.4 \mathrm{~V}$ both with GF/C and GF/F separators.

Figure 6. Evolution during cycling at $40{ }^{\circ} \mathrm{C}$ and $0.1 \mathrm{~mA} \cdot \mathrm{cm}^{-2}$ of a $\mathrm{PYR}_{1201}$ FSI-based cell incorporating a GF/C separator (a) Voltage profile of a GF/C cell; and (b) Evolution of the impedance spectra at $21^{\circ} \mathrm{C}$ of the $\mathrm{GF} / \mathrm{C}$ cell.
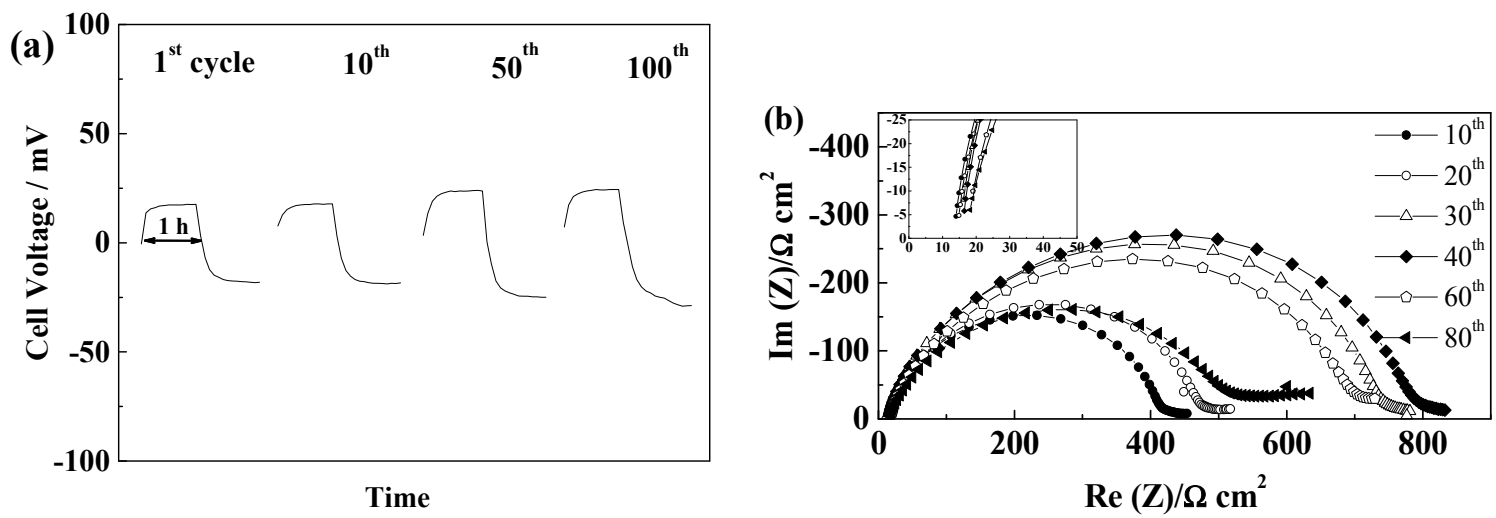


\subsubsection{Celgard $^{\circledR} 2500$ and Celgard $^{\circledR} 2325$}

For the microporous separators Celgard ${ }^{\circledR} 2500$ and Celgard ${ }^{\circledR} 2325$, only the TFSI $^{-}$based ILs led to proper wetting and subsequent cycling of the cells. As seen in Figure 7a,b, the two separators led to similar voltage profiles with PYR $_{14}$ TFSI, with steady-states reached quickly, in accordance with their low thickness. The cycling voltages were lower as compared with GF separators, especially for Celgard ${ }^{\circledR} 2500$. The lower thickness of these separators allows reaching the steady state faster (and lower values), an increase of SEI resistance resulting in this case to a significant increase of ohmic drop, seen as voltage drop when the current is reversed. However, the voltage increase after that first step, linked to $\mathrm{Li}^{+}$mass transport by diffusion (noted $\Delta \mathrm{V}_{\mathrm{D}}$ ), is not overly modified by the SEI changes.

In the case of Celgard ${ }^{\circledR} 2325$, we observe in Figure $7 \mathrm{~b}$ a slow increase of cell voltage from 55 to $77 \mathrm{mV}$ over 100 cycles, while the SEI resistance (Figure 7d) was rather constant over the whole 100 cycles. In this case, it seems that the lower porosity of the separator induces more marked mass transport limitations, as $\Delta \mathrm{V}_{\mathrm{D}-100}>\Delta \mathrm{V}_{\mathrm{D}-10}$, which in this case, increases during cycling whereas the electrolyte resistance is almost constant.

Figure 7. Evolution of $\mathrm{PYR}_{14}$ TFSI-based electrolyte cells during cycling at $40{ }^{\circ} \mathrm{C}$ and $0.1 \mathrm{~mA} \cdot \mathrm{cm}^{-2}$ (a) Voltage profiles of a Celgard ${ }^{\circledR} 2500$ cell; (b) Voltage profile of a Celgard ${ }^{\circledR} 2325$ cell; (c) Evolution of the impedance spectra at $21{ }^{\circ} \mathrm{C}$ of a Celgard ${ }^{\circledR} 2500$ cell; and (d) Evolution of the impedance spectra at $21^{\circ} \mathrm{C}$ of a Celgard ${ }^{\circledR} 2325$ cell.
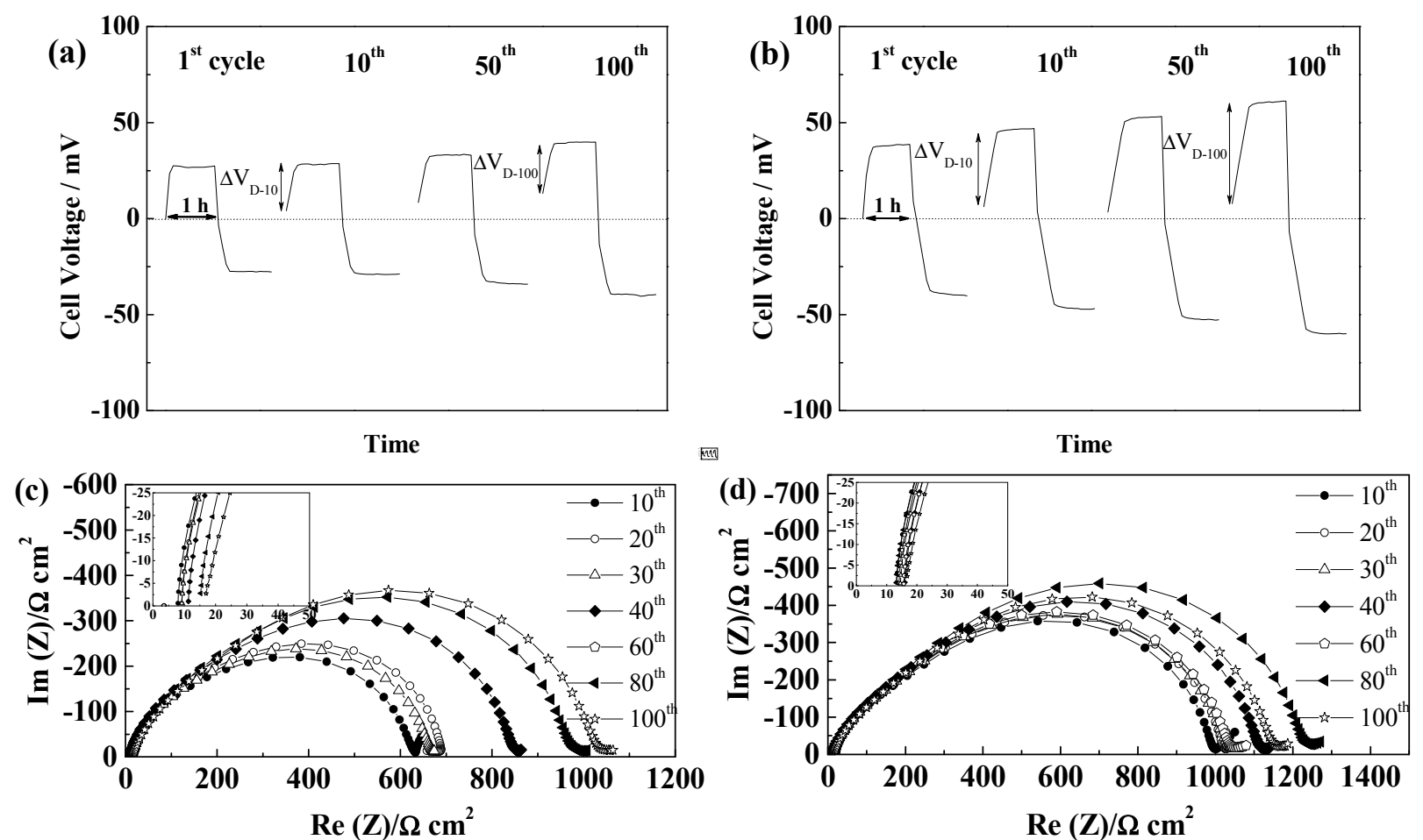

For PYR ${ }_{1201}$ TFSI, the vacuum applied during pouch cell sealing allowed good electrolyte wetting of the Celgard ${ }^{\circledR}$ separators and, as a result, the cell voltages were lower as compared with PYR ${ }_{14}$ TFSI, in accordance with the higher conductivity of the electrolyte (See Table 3), as illustrated in Figure 8. With this electrolyte, although the variation of the voltage profiles resembles that of $\mathrm{PYR}_{14} \mathrm{TFSI}$, with 
a more marked increase of cell voltage with Celgard ${ }^{\circledR} 2500$. However, the resistances of the electrolyte (Figure 8c,d), initially rather low, increase to higher values than those obtained either with PYR ${ }_{14}$ TFSI, or using 10 times thicker GF separators. Nevertheless, the cells reached 100 cycles and finally led to similar plating voltage as for GF separators. This confirms the poorer SEI forming properties of $\mathrm{PYR}_{12 \mathrm{O} 1}$ TFSI, as compared to $\mathrm{PYR}_{14} \mathrm{TFSI}$, which is especially visible with thin separators as a result of the smaller electrolyte reservoir they constitute.

Figure 8. Evolution of $\mathrm{PYR}_{12 \mathrm{O} 1}$ TFSI-based electrolyte cells during cycling at $40{ }^{\circ} \mathrm{C}$ and $0.1 \mathrm{~mA} \cdot \mathrm{cm}^{-2}$ (a) Voltage profiles of a Celgard ${ }^{\circledR} 2500$ cell; (b) Voltage profile of a Celgard $^{\circledR} 2325$ cell; (c) Evolution of the impedance spectra at $21{ }^{\circ} \mathrm{C}$ of a Celgard ${ }^{\circledR} 2500$ cell; and (d) Evolution of the impedance spectra at $21^{\circ} \mathrm{C}$ of a Celgard ${ }^{\circledR} 2325$ cell.
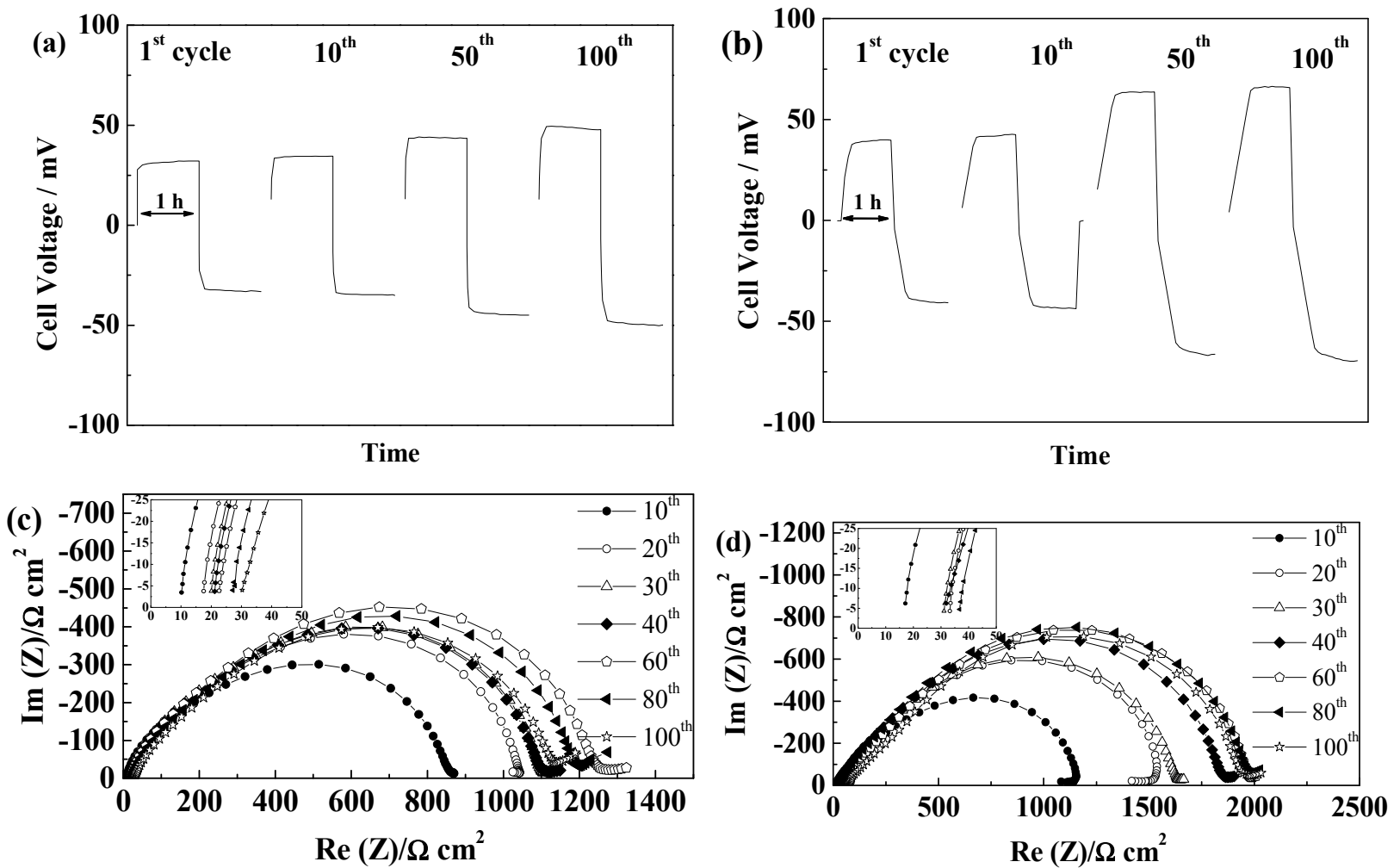

For PYR ${ }_{14}$ TFSI combined with Celgard ${ }^{\circledR} 2325$, the SEM images of the Li surface after cycling are shown in Figure 9a,b, indicate that, if the Li surface is not overly modified as a whole, some cracks of ca. 1-2 $\mu \mathrm{m}$ can be seen, within which inhomogeneous Li deposition seems to occur. The rest of the Li surface still presents a marble-like texture, which is "native" on the Li foil before cell assembly. Li deposition occurs through this unmodified part of the SEI, finally inducing some cracks of limited impact (although a limited SEI resistance decrease is seen in Figure 7d), despite the possible shortcuts for $\mathrm{Li}^{+}$transport through the generated SEI cracks. In this case, there is no obvious link between the separator morphology and the crack's pattern, in accordance with the smooth morphology of the separator while the overall volumes variation over cycling could be at the origin of these cracks. 
Figure 9. SEM images of the Li surface after 100 cycles, using a 10 mol\% LiTFSI $\mathrm{PYR}_{14}$ TFSI and a Celgard ${ }^{\circledR} 2325$ separator.
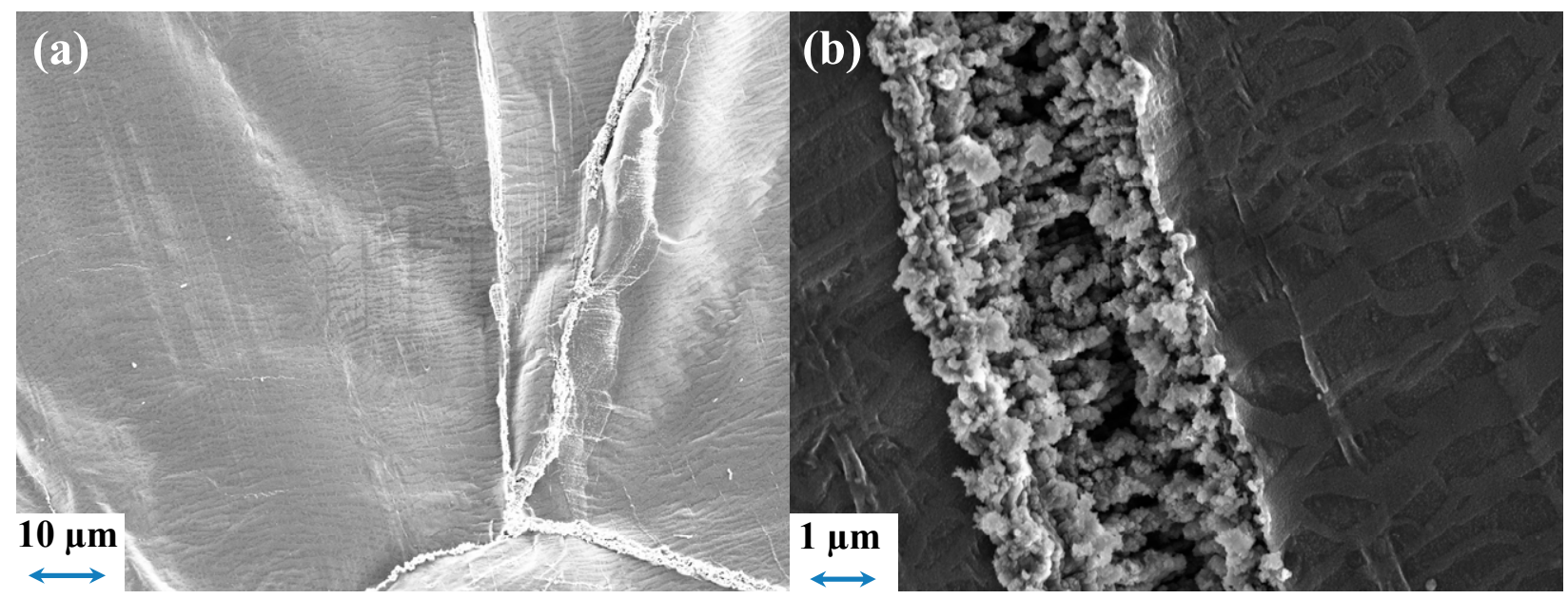

\subsubsection{Freudenberg FS2190}

Overall, Freudenberg FS2190 led to short-circuits for many cells, especially those with FSI-based electrolytes, which could be linked to the poor affinity of PP with the electrolyte. Indeed, as seen with the evolution of the SEI resistance, the large FS2190 fibers induce extended cracking of the "native" SEI, which could a priori be repaired, given the good SEI forming properties of the FSI based electrolytes. However, the poor wetting of the fibers by FSI- based ILs might induce poorer access and increased inhomogeneities in local current densities in the vicinity of the fibers in contact with Li and punctual shorts-circuits during cycling. The presence of dendrites was confirmed by the EIS measurements, showing first a growing impedance, more marked in the case of $\mathrm{PYR}_{14} \mathrm{FSI}$ than for $\mathrm{PYR}_{12 \mathrm{O}} \mathrm{FSI}$, followed, in many cells, by sudden decreases, due to dendrites growth, as illustrated in Figure 10 (although no short is visible in the impedance spectra).

Figure 10. Evolution of the impedance spectra at $21{ }^{\circ} \mathrm{C}$ of Freudenberg FS2190 cells during cycling at $40{ }^{\circ} \mathrm{C}$ and $0.1 \mathrm{~mA} \cdot \mathrm{cm}^{-2}$ (a) $\mathrm{PYR}_{14} \mathrm{FSI}$ cell; and (b) $\mathrm{PYR}_{1201} \mathrm{FSI}$ cell.
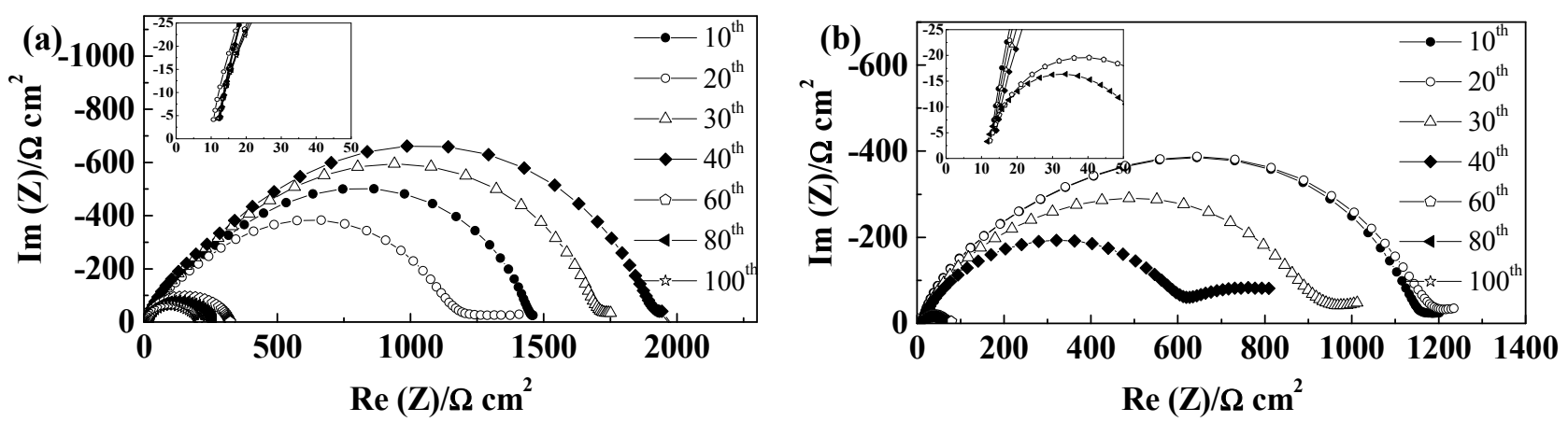

For TFSI-based electrolytes, cycling without short circuits could be obtained. In combination with PYR $_{14}$ TFSI (Figure 11a), the cells showed a continuous increase of cell voltage, starting from $100 \mathrm{mV}$ to reach $167 \mathrm{mV}$ after 100 cycles, as a result of the higher initial SEI resistance and its dramatic 
increase upon cycling shown in Figure 11c. In this case also, an increase of $\Delta V_{D}$ can be observed with cycling in addition to increased ohmic drop.

The use of PYR 1201 TFSI showed even higher cell voltages, from 147 to $307 \mathrm{mV}$ resulting from an even more dramatic SEI resistance growth (Figure 11d).

Figure 11. Evolution of Freudenberg FS2190 cells during cycling at $40{ }^{\circ} \mathrm{C}$ and $0.1 \mathrm{~mA} \cdot \mathrm{cm}^{-2}$ (a) Voltage profiles of PYR 14 TFSI cell; (b) Voltage profile of a PYR $_{1201}$ TFSI cell; (c) Evolution of the impedance spectra of the PYR ${ }_{14}$ TFSI cell; and (d) Evolution of the impedance spectra at $21^{\circ} \mathrm{C}$ of the PYR ${ }_{12 \mathrm{O} 1}$ TFSI cell.
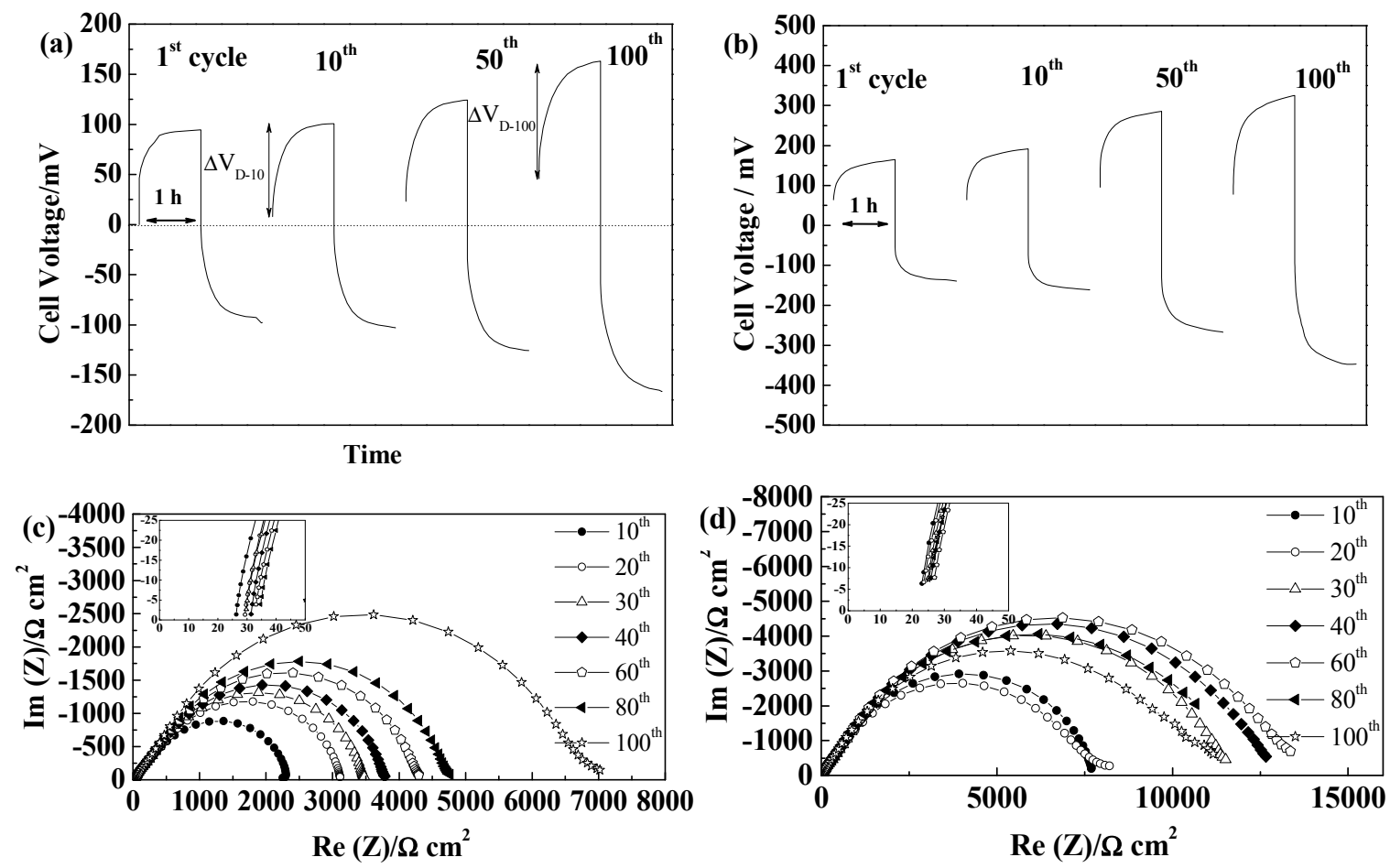

To confirm the impact of the separator morphology on the SEI/electrolyte interface, some SEM images of the $\mathrm{Li}$ foil from the PYR 14 TFSI cell were acquired and are shown in Figure 12. Some large features with similar dimensions to that of the PP fiber of FS2190 can be seen in Figure 12a. From the images it is observed a change of surface morphology around these features probably due to the accumulation of electrolyte degradation product, which had previously been suggested to lead to additional mass transport limitation during longer term cycling [44]. In other areas, less damaged, smaller features (alignment of small globular dendrites) can also be seen (Figure 12b), however, the surface is still mostly unchanged and the marble-like original morphology mostly preserved. One can suppose that the thickening of the SEI around the damaged area would have induced an increase in current density, triggering dendrite growth as a result of $\mathrm{Li}^{+}$local depletion. 
Figure 12. SEM images of the Li surface after 100 cycles, using a 10 mol\% LiTFSI PYR $_{14}$ TFSI and a Freudenberg FS2190 separator.

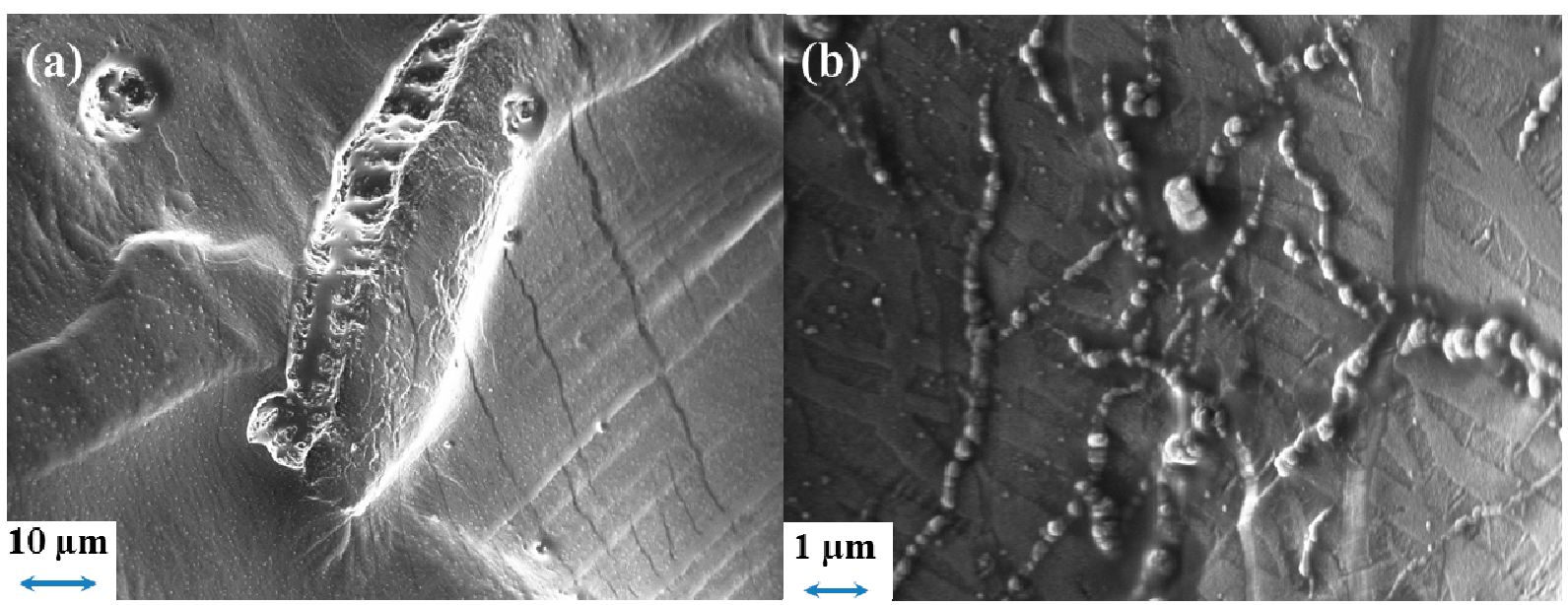

\subsubsection{Separion ${ }^{\circledR}$}

The inorganic composite separator Separion ${ }^{\circledR}$ allows Li cycling in combination with PYR $_{14}$ TFSI-based electrolyte with, however, the steady increase in cell voltage from 41 to $74 \mathrm{mV}$ over 100 cycles shown in Figure 13a. This is probably due to the continuous increase of the SEI resistance, concomitant with an increase of the electrolyte resistance, as seen in Figure 13b. The inorganic particles at the surface of Separion ${ }^{\circledR}$, although smaller than the fibers of FS2190 are likely to induce well dispersed cracks within the SEI, which could explain the continuous increase of the SEI and electrolyte resistance, as a result of a marked reactivity when using TFSI-based ILs.

Figure 13. Evolution of a $\left(\mathrm{PYR}_{14} \mathrm{TFSI}+\right.$ Separion $\left.^{\circledR}\right)$ cell during cycling at $40{ }^{\circ} \mathrm{C}$ and $0.1 \mathrm{~mA} \cdot \mathrm{cm}^{-2}$ (a) Voltage profiles; and (b) Evolution of the impedance spectra at $21^{\circ} \mathrm{C}$.
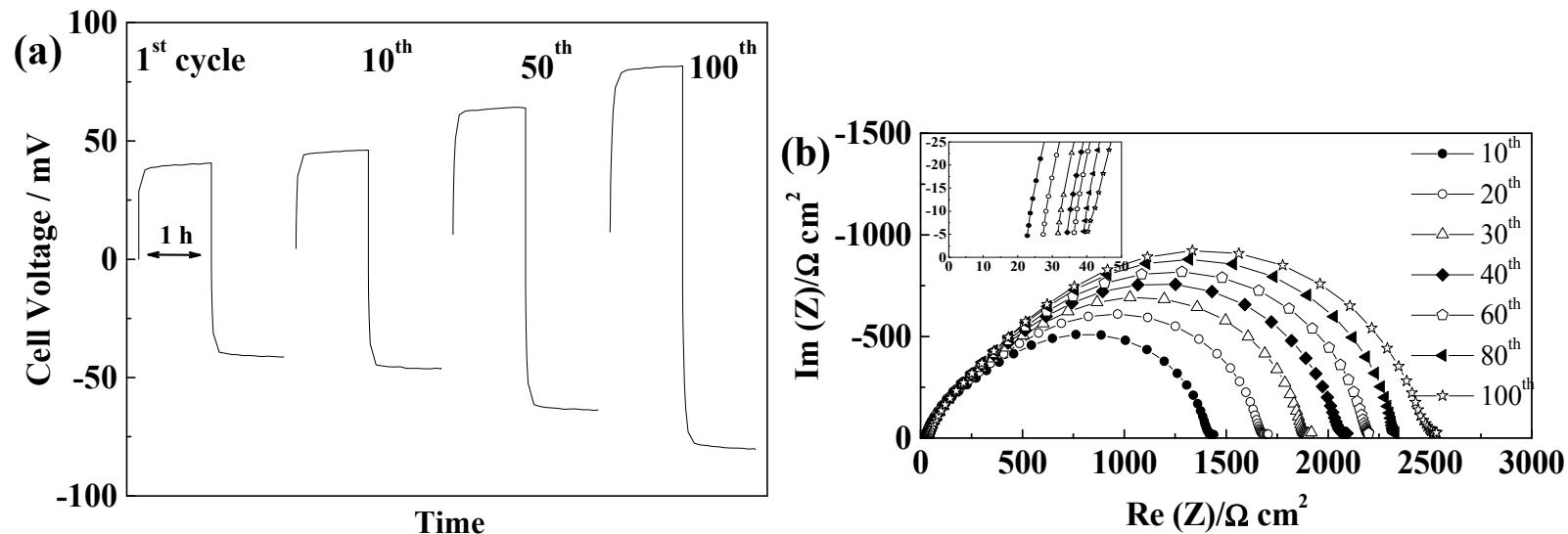

In the case of the PYR 1201 TFSI, high initial cell voltages were obtained and after few cycles, depending on cells, unstable voltage profile, resulting from pronounced interfacial reactivity. Short circuits could be seen in most cells, which illustrate further the lower SEI forming ability of this electrolyte, although we cannot exclude that stable cycling could have been reached with different "native" SEI or improved interface stabilization. If Separion ${ }^{\circledR}$ allows cycling with PYR $_{14}$ TFSI, a continuous increase of SEI resistance is seen for PYR P $_{1201}$ TFSI, thus resulting in poor cycling 
performance. Thus, it can be summarized that the rough and non-flexible surface of Separion ${ }^{\circledR}$ significantly impact the SEI evolution during cycling. On the other hand, the electrolytes with better SEI building ability, $\mathrm{PYR}_{14} \mathrm{FSI}$ and $\mathrm{PYR}_{12 \mathrm{O} 1} \mathrm{FSI}$, allowed rather stable performance with Separion ${ }^{\circledR}$, as illustrated in Figure 14. With PYR ${ }_{14} \mathrm{FSI}$, an increase followed by stabilization of the SEI resistance is observed while almost no changes in electrolyte conductivity are observed (Figure 14c), which results in the stable cell voltage during cycling seen in Figure 14a. It can be noticed that only the ohmic drop increases in this case, but not the diffusive part.

PYR $_{1201}$ FSI presents excellent cycling behavior, as seen in Figure 14b, when combined with Separion $^{\circledR}$, as a combination of its high conductivity, good SEI formation ability, good affinity for the separator, and low thickness of the ensemble. Steady-state current were reached within minutes and the steady-state voltage did not vary in 100 cycles, showing that, even if the SEI resistance increases over cycling (at $20^{\circ} \mathrm{C}$ ) (Figure 14d). At the cycling temperature, no influence of these change can be seen in the voltage profiles while the total resistance of the two SEI stays below $800 \Omega \mathrm{cm}^{2}$ with a slight increase followed by a limited decrease. It is worth pointing out that the combination Separion + $\mathrm{PYR}_{12 \mathrm{O} 1} \mathrm{FSI}$ allowed outstanding performance in these conditions, which show that, even when the "native" SEI is strongly damaged, and especially in this case, with stable plating voltages in the $10-15 \mathrm{mV}$ range, and confirms its excellent SEI forming ability.

Figure 14. Evolution of Separion ${ }^{\circledR}$ cells during cycling at $40{ }^{\circ} \mathrm{C}$ and $0.1 \mathrm{~mA} \cdot \mathrm{cm}^{-2}$ (a) Voltage profiles of a PYR ${ }_{14} \mathrm{FSI}$ cell; (b) Voltage profile of a $\mathrm{PYR}_{12 \mathrm{O} 1 \mathrm{FSI}}$ cell; (c) Evolution of the impedance spectra at $20^{\circ} \mathrm{C}$ of a PYR ${ }_{14} \mathrm{FSI}$ cell; and (d) Evolution of the impedance spectra at $20{ }^{\circ} \mathrm{C}$ of a PYR ${ }_{1201}$ FSI cell.
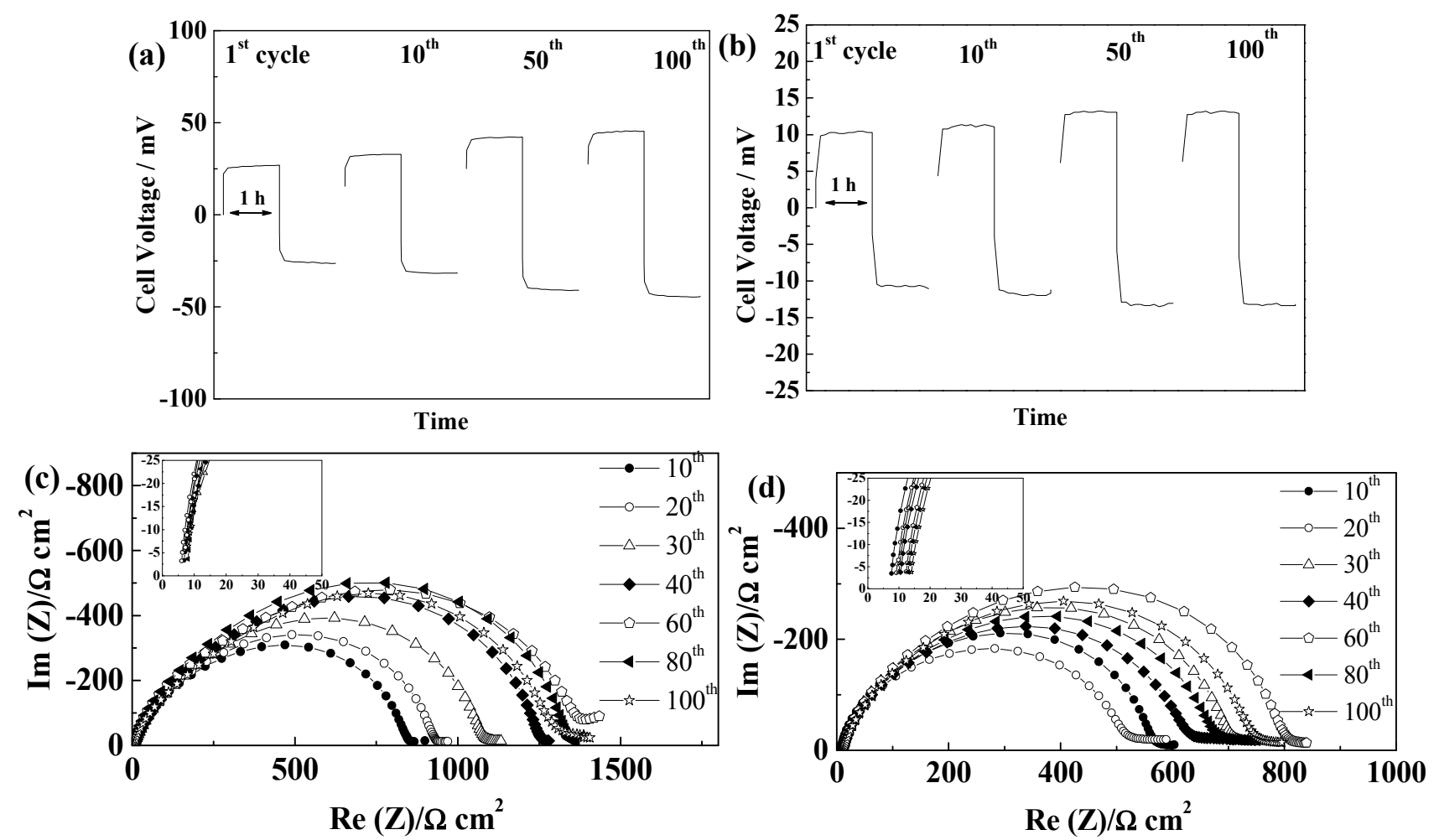


\subsubsection{Cellulose "Copa Spacer”}

Cellulose is, a priori, not chemically inert in contact with Li metal, given the large number of protons present on the polymer backbone. Nevertheless, as in any case the stability and self repair of the SEI is the key of stable Li cycling, the use of cellulose as electrolyte separator was tested. Most cells developed dendrites, probably because of a too high and inhomogeneous reactivity. Nevertheless, in some cases, it was possible to strip and plate lithium rather steadily. In Figure 15a is represented an example of cycling behavior (although highly variable) obtained with the PYR $_{14}$ TFSI-based electrolyte. Notably, the first 10 cycles were rather stable, with no marked changes in the voltage profile and the fast obtaining of steady-state voltage. Unfortunately, after the first stop for impedance measurement, the cells became less stable with cycling and the voltage started increasing. A more stable cycling was then reached, with a moderate voltage growth with cycling. Accordingly, the impedance spectra in Figure 14b reveal a first increase of the SEI resistance, followed by the stabilization of the SEI and, in fine, a rather strong increase. One can also notice in the 100th cycle that the voltage is decreasing, which is an indication for inhomogeneous deposition.

Figure 15. Evolution of a (Cellulose + PYR 14 TFSI) cell during cycling at $40{ }^{\circ} \mathrm{C}$ and $0.1 \mathrm{~mA} \cdot \mathrm{cm}^{-2}$ (a) Voltage profiles; and (b) Evolution of the impedance spectra at $20^{\circ} \mathrm{C}$.
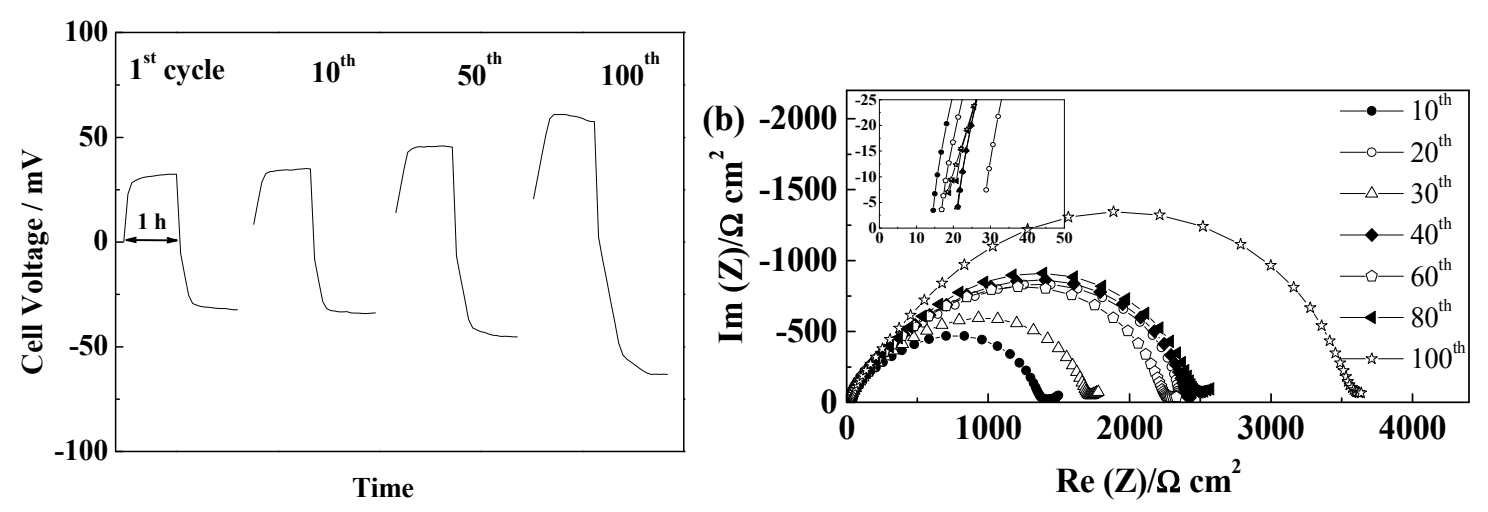

\section{Experimental}

\subsection{Preparation of Ionic Liquid Based Electrolytes}

Four ionic liquids (ILs) made of combinations of the $N$-butyl- $N$-methylpyrrolidinium $\left(\mathrm{PYR}_{14}{ }^{+}\right)$and $N$-methoxyethyl- $N$-methylpyrrolidinium $\left(\mathrm{PYR}_{12 \mathrm{Ol}}{ }^{+}\right)$, paired with bis(fluorosulfonyl)imide ( $\mathrm{FSI}^{-}$) and bis(trifluoromethanesulfonyl)imide ( $\mathrm{TFSI}^{-}$), shown in Figure 16. The ILs were synthesized as previously reported [46,47], using $N$-methylpyrrolidine (97\%), 1-bromobutane (99\%) and ethylacetate (ACS grade, $>99.5 \mathrm{wt} \%$ ) as received. 2-bromoethyl methyl ether (>85 wt \%) was distilled shortly before use. All these chemicals were from Sigma-Aldrich, St. Louis, MO, USA. Potassium bis(fluorosulfonyl)imide (KFSI, Dai-Ichi Kogyo Seiyaku Co., Kyoto, Japan) and LiTFSI (3M, St. Paul, MN, USA) were used as received for IL syntheses. The resulting ILs were all colorless liquids at room temperature. Their purity was checked by ${ }^{1} \mathrm{H}$ NMR for organics while ICP-OES showed halide content below $20 \mathrm{ppm}$. The ILs including $\mathrm{PYR}_{12 \mathrm{O} 1}{ }^{+}$(resp. $\mathrm{PYR}_{14}{ }^{+}$) were dried at $80{ }^{\circ} \mathrm{C}$ (resp. $100{ }^{\circ} \mathrm{C}$ ) at $10^{-3} \mathrm{mBar}$ for $24 \mathrm{~h}$ and then at $p<10^{-7} \mathrm{mBar}$ for $24 \mathrm{~h}$. The electrolytes were prepared by stirring 
(under vacuum $<10^{-7} \mathrm{mBar}$ ) at $60^{\circ} \mathrm{C}$ ) the pre-dried ILs and LiTFSI (dried for $24 \mathrm{~h}$ at $p<10^{-7} \mathrm{mBar}$ at $120^{\circ} \mathrm{C}$ ) in a 9:1 molar ratio. The IL-based electrolytes were then stored in glass vessels in a desiccator inside a dry room with relative humidity below $0.1 \%$ at $21{ }^{\circ} \mathrm{C}$.

Figure 16. Molecular formulae of $\mathrm{PYR}_{14}{ }^{+}, \mathrm{PYR}_{12 \mathrm{O} 1}{ }^{+}, \mathrm{FSI}^{-}$and $\mathrm{TFSI}^{-}$.

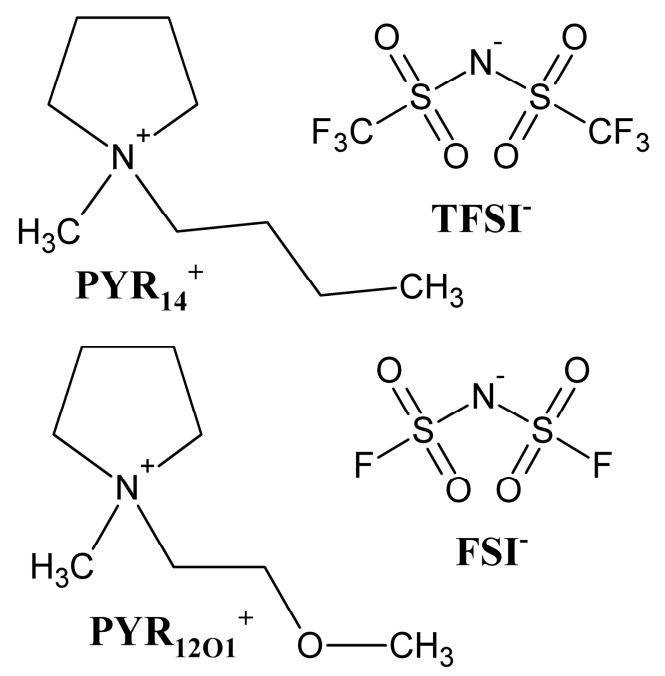

The ionic conductivities of the IL based electrolytes, measured using a MMates AC conductimeter are listed in Table 3.

Table 3. Conductivity of the electrolytes at $20^{\circ} \mathrm{C}$.

\begin{tabular}{ll}
\hline Electrolyte & $\boldsymbol{\sigma}\left(\mathbf{2 0}{ }^{\circ} \mathbf{C}\right) / \mathbf{S} \cdot \mathbf{c m}^{-\mathbf{1}}$ \\
\hline PYR $_{14}$ FSI:LiTFSI $(9: 1)$ & $2.23 \times 10^{-3}$ \\
PYR $_{14}$ TFSI:LiTFSI (9:1) & $1.07 \times 10^{-3}$ \\
PYR $_{1201}$ FSI:LiTFSI $(9: 1)$ & $3.94 \times 10^{-3}$ \\
PYR $_{1201}$ TFSI:LiTFSI $(9: 1)$ & $2.09 \times 10^{-3}$ \\
\hline
\end{tabular}

\subsection{Separators Characterizations}

The separators were dried under vacuum for at least $48 \mathrm{~h}$, at $70{ }^{\circ} \mathrm{C}$ excepted for the glass fiber separators and Separion ${ }^{\circledR}$, which were dried at $100^{\circ} \mathrm{C}$.

The separators thicknesses, listed in Table 1, were measured using a Mitutoyo micrometer thickness gauge (average of 5 measurements) while the Gurley numbers were measured using a 4110N GENUINE GURLEY Densometer (Gurley Precision Instruments, Troy, NY, USA). The measurements were repeated ten times.

Except for the air permeability measurements and SEM imaging, all measurements and cell preparations were performed inside a dry room with humidity below $0.1 \%$ at $21{ }^{\circ} \mathrm{C}$.

The wettability of the separators was assessed by following the contact angles of electrolyte drop deposited on the surface of the separators using a Drop Shape Analysis system (DSA100S, Krüss, Hamburg, Germany). The measurements were repeated three times. 


\subsection{Electrochemical Measurements}

The ionic conductivity (McMullin numbers) was measured as follow: The Celgard ${ }^{\circledR}$ membranes were soaked in the electrolyte for $12 \mathrm{~h}$ while the other separators required only 15 min wetting prior to the conductivity measurements. Stacks from 1 to 5 separators were then placed between two stainless-steel electrodes (12 mm diameter) and their resistance was measured by electrochemical impedance spectroscopy (EIS) using a Solartron 1260 Frequency Response Analyser (Solartron Analytical, Farnborough, UK). The McMullin numbers (ratio of the resistivity of the separator soaked with electrolyte to the resistivity of the electrolyte itself, $N \mathrm{~m}$ ) were then calculated [48].

Symmetrical $\mathrm{Li} /($ electrolyte + separator)/Li pouch cells were assembled using two $50 \mu \mathrm{m} \mathrm{Li}$ foils (99.999\%, Rockwood Lithium GmbH, Frankfurt am Main, Germany), nickel current collectors and sealed under vacuum in pouch bag cells in the dry-room. The cells were then stored for three days at $21{ }^{\circ} \mathrm{C}$ and their impedance were monitored by EIS.

Galvanostatic Li plating/stripping tests were performed at $40{ }^{\circ} \mathrm{C}$ in a climatic chamber (MK53, Binder GmbH, Tuttlingen, Germany). A current density of $0.1 \mathrm{~mA} \cdot \mathrm{cm}^{-2}$ was applied using a S4000 battery cycler (Maccor Inc., Tulsa, OK, USA), reversing the polarity every hour. Electrochemical impedance spectroscopy (EIS) measurements were then acquired at $21^{\circ} \mathrm{C}$, after the 10 th, 20th, 30th, 40th, 60th, 80th, and 100th cycles. The cycling of the cells was resumed after temperature equilibration for at least one hour after each impedance measurement.

\subsection{Scanning Electron Microscopy (SEM) Imaging}

SEM images of the separators were taken using a SEM Auriga (Carl Zeiss, Jena, Germany) after sputtering with gold. The images of the Li electrode after cycling were taken after disassembling the cells in the dry room and rinsing of the Li electrode using dimethyl carbonate. The electrodes were then transferred to the SEM chamber using a sealed cell.

\section{Conclusions}

The systematic study of separators for IL-based electrolyte ensembles allowed finding alternatives to GF separators for safe Li-ion batteries. It was shown that Celgard 2500 is a valid practical alternative to glass fiber separator for TFSI-based ILs while FSI-based IL only poorly wet polyolefin separators. Separion ${ }^{\circledR}$ (or other hydrophilic separators) is thus more versatile choice for Li-ion batteries than non-functionalized polyolefin for all tested hydrophobic ILs, considering that the SEI building on graphite would not "a priori" be much influenced much by the separator morphology, given the limited surface area in contact and the lack of pre-existing SEI prior to the first charge. Moreover, studying the (separator + electrolyte) properties toward Li metal and Li metal cycling allowed drawing the following conclusions:

A scale for SEI-forming properties, based on the 0.1 LiTFSI-0.9 IL electrolytes behaviors with different separators could be proposed and the electrolyte with the highest conductivity, $\mathrm{PYR}_{1201} \mathrm{FSI}$, allowed the best performance. As a consequence, Separion ${ }^{\circledR}$, which is not favorable for Li metal cycling when combined with TFSI-based electrolytes, due to its rough ceramic surface inducing extended damages within the "native" SEI, led to the best Li cycling results when combined with 
PYR $_{1201}$ FSI, probably thanks to the formation of an effective SEI as a combination of initial SEI damage and evolution in contact with the electrolyte.

The morphology of the separator is of particular importance: Given the presence of a pre-existing SEI, the roughness of the separator influence the evolution the SEI after the initial contact, which then evolves, depending on the reactivity of the (electrolyte + separator) combination. SEM images confirmed the electrochemical results and evidenced that, in PYR ${ }_{14}$ TFSI, a thicker SEI is deposited close to where significant damage of the SEI occurs while, in less damaged areas, the original surface morphology is barely modified.

\section{Acknowledgments}

This work was supported by the European Commission within the FP7 Project LABOHR (FP7-NMP-2010, grant agreement no. 265971).

\section{Author Contributions}

M.K. performed the experimental work with the help of J.Z. and wrote the manuscript. E.P. and S.P. supervised the study and revised the manuscript.

\section{Conflicts of Interest}

The authors declare no conflict of interest.

\section{References}

1. Jacobson, M.Z.; Delucchi, M.A. A Path to sustainable energy by 2030. Sci. Am. 2009, 301, 58-65.

2. Jacobson, M.Z.; Delucchi, M.A. Providing all global energy with wind, water, and solar power, Part I: Technologies, energy resources, quantities and areas of infrastructure, and materials. Energy Policy 2011, 39, 1154-1169.

3. Delucchi, M.A.; Jacobson, M.Z. Providing all global energy with wind, water, and solar power, Part II: Reliability, system and transmission costs, and policies. Energy Policy 2011, 39, 1170-1190.

4. Fong, R.; von Sacken, U.; Dahn, J.R. Studies of lithium intercalation into carbons using nonaqueous electrochemical cells. J. Electrochem. Soc. 1990, 137, 2009-2013.

5. Peled, E. The electrochemical behavior of alkali and alkaline earth metals in nonaqueous battery systems - The solid electrolyte interphase model. J. Electrochem. Soc. 1979, 126, 2047-2051.

6. Doughty, D.; Roth, P. A general discussion of Li ion battery safety. Electrochem. Soc. Interface 2012, 21, 37-44.

7. Arai, H.; Tsuda, M.; Saito, K.; Hayashi, M.; Sakurai, Y. Thermal reactions between delithiated lithium nickelate and electrolyte solutions. J. Electrochem. Soc. 2002, 149, 401-406.

8. Zinigrad, E.; Larush-Asraf, L.; Gnanaraj, J.S.; Sprecher, M.; Aurbach, D. On the thermal stability of LiPF 6 . Thermochim. Acta 2005, 438, 184-191.

9. Campion, C.L.; Li, W.; Lucht, B.L. Thermal decomposition of $\mathrm{LiPF}_{6}$-based electrolytes for lithium-ion batteries. J. Electrochem. Soc. 2005, 152, 2327-2334. 
10. Barlowz, C.G. Reaction of water with hexafluorophosphates and with Li bis(perfluoroethylsulfonyl) imide salt. Electrochem. Solid State Lett. 1999, 2, 362-364.

11. Yang, H.; Zhuang, G.V.; Ross Jr., P.N. Thermal stability of LiPF 6 salt and Li-ion battery electrolytes containing $\mathrm{LiPF}_{6}$. J. Power Sources 2006, 161, 573-579.

12. Vetter, J.; Novak, P.; Wagner, M.R.; Veit, C.; Möller, K.-C.; Besenhard, J.O.; Winter, M.; Wohlfahrt-Mehrens, M.; Vogler, C.; Hammouche, A. Ageing mechanisms in lithium-ion batteries. J. Power Sources 2005, 147, 269-281.

13. Armand, M. Materials for Advanced Batteries; Plenum Press: New York, NY, USA, 1980.

14. Lewandowski, A.; Swiderska-Mocek, A. Ionic liquids as electrolytes for Li-ion batteries-An overview of electrochemical studies. J. Power Sources 2009, 194, 601-609.

15. Armand, M.; Tarascon, J.-M. Building better batteries. Nature 2008, 451, 625-657.

16. Borgel, V.; Markevich, E.; Aurbach, D.; Semrau, G.; Schmidt, M. On the thermal behavior of model $\mathrm{Li}-\mathrm{LixCoO} 2$ systems containing ionic liquids in standard electrolyte solutions, J. Power Sources 2009, 189, 331-336.

17. Armand, M.; Endres, F.; MacFarlane, D.R.; Ohno, H.; Scrosati, B. Ionic-liquid materials for the electrochemical challenges of the future. Nat. Mater. 2009, 8, 621-629.

18. Holzapfel, M.; Jost, C.; Novak, P. Stable cycling of graphite in an ionic liquid based electrolyte. Chem. Commun. 2004, 18, 2098-2099.

19. Sato, T.; Maruo, T.; Marukane, S.; Takagi, K. Ionic liquids containing carbonate solvent as electrolytes for lithium ion cells, J. Power Sources 2004, 138, 253-261.

20. Ishikawa, M.; Sugimoto, T.; Kikuta, M.; Ishiko, E.; Kono, M. Pure ionic liquid electrolytes compatible with a graphitized carbon negative electrode in rechargeable lithium-ion batteries. J. Power Sources 2006, 162, 658-662.

21. Sugimoto, T.; Kikuta, M.; Ishiko, E.; Kono, M.; Ishikawa, M. Ionic liquid electrolytes compatible with graphitized carbon negative without additive and their effects on interfacial properties. J. Power Sources 2008, 183, 436-440.

22. Sugimoto, T.; Atsumi, Y.; Kikuta, M.; Ishiko, E.; Kono, M.; Ishikawa, M. Ionic liquid electrolyte systems based on bis(fluorosulfonyl)imide for lithium-ion batteries. J. Power Sources 2009, 189, 802-805.

23. Guerfi, A.; Duchesne, S.; Kobayashi, Y.; Vijh, A.; Zaghib, K. $\mathrm{LiFePO}_{4}$ and graphite electrodes with ionic liquids based on bis(fluorosulfonyl)imide (FSI) - For Li-ion batteries. J. Power Sources 2008, 175, 866-873.

24. Matsumoto, H.; Sakaebe, H.; Tatsumi, K.; Kikuta, M.; Ishiko, E.; Kono, M. Fast cycling of $\mathrm{Li} / \mathrm{LiCoO}_{2}$ cell with low-viscosity ionic liquids based on bis(fluorosulfonyl)imide (FSI) ${ }^{-}$ J. Power Sources 2006, 160, 1308-1313.

25. Zhou, Q.; Henderson, W.A.; Appetecchi, G.B.; Montanino, M.; Passerini, S. Physical and electrochemical properties of $\mathrm{N}$-alkyl- $\mathrm{N}$-methylpyrrolidinium bis(fluorosulfonyl)imide ionic liquids: PY ${ }_{13}$ FSI and PY ${ }_{14}$ FSI. J. Phys. Chem. 2008, 112, 13577-13580.

26. Paillard, E.; Zhou, Q.; Henderson, W.A.; Appetecchi, G.B.; Montanino, M.; Passerini, S. Electrochemical and physicochemical properties of PY ${ }_{14} \mathrm{FSI}$-based electrolytes with LiFSI. J. Electrochem. Soc. 2009, 156, A891-A895. 
27. Howlett, P.C.; MacFarlane, D.R.; Hollenkamp, A.F. High lithium metal cycling efficiency in a room-temperature ionic liquid. Electrochem. Solid State Lett. 2004, 7, A97-A101.

28. Kim, G.-T.; Appetecchi, G.B.; Montanino, M.; Alessandrini, F.; Passerini, S. Long-term cyclability of lithium metal electrodes in ionic liquid-based electrolytes at room temperature. ECS Trans. 2010, 25, 127-138.

29. Zhang, J.; Liu, Z.; Kong, Q.; Zhang, C.; Pang, S.; Yue, L.; Wang, X.; Yao, J.; Cui, G. Mussel inspired modification of polypropylene separators by catechol/polyamine for Li-ion batteries. ACS Appl. Mater. Interfaces 2012, 5, 128-134.

30. Zhang, S.S. A review on the separators of liquid electrolyte Li-ion batteries, J. Power Sources 2007, 164, 351-364.

31. Venugopal, G.; Moore, J.; Howard, J.; Pendalwar, S. Characterization of microporous separators for lithium-ion batteries. J. Power Sources 1999, 77, 34-41.

32. Arora, P.; Zhang, Z.J. Battery separators. Chem. Rev. 2004, 104, 4419-4462.

33. Hennige, V.; Hying, C.; Hoerpel, G.; Novak, P.; Vetter, J. Separator provided with asymmetrical pore structures for an electrochemical cell. U.S. Patent 7,709,140, 4 May 2010.

34. Kuribayashi, I. Characterization of composite cellulosic separators for rechargeable lithium-ion batteries. J. Power Sources 1996, 63, 87-91.

35. Jabbour, L.; Destro, M.; Chaussy, D.; Gerbaldi, C.; Penazzi, N.; Bodoardo, S.; Beneventi, D. Flexible cellulose/LiFePO 4 paper-cathodes: Toward eco-friendly all-paper Li-ion batteries. Cellulose 2013 20, 571-582.

36. Peled, E.; Golodnitsky, D.; Ardel, G.; Eshkenazy, V. The SEI model-application to lithium-polymer electrolyte batteries. Electrochim. Acta 1995, 40, 2197-2204.

37. Chazalviel, J.-N. Electrochemical aspects of the generation of ramified metallic electrodeposits. Phys. Rev. A 1990, 42, 7355-7367.

38. Brissot, C.; Rosso, M.; Chazalviel, J.-N.; Lascaud, S. Dendritic growth mechanisms in lithium/polymer cells. J. Power Sources 1999, 925, 81-82.

39. Rosso, M.; Gobron, T.; Brissot, C.; Chazalviel, J.-N.; Lascaud, S. Onset of dendritic growth in lithium/polymer cells. J. Power Sources 2001, 804, 97-98.

40. Reiter, J.; Paillard, E.; Grande, L.; Winter, M.; Passerini, S. Physicochemical properties of $\mathrm{N}$-methoxyethyl- $\mathrm{N}$-methylpyrrolidinum ionic liquids with perfluorinated anions. Electrochim. Acta 2013, 91, 101-107.

41. Maier, J. Defect chemistry and conductivity effects in heterogeneous solid electrolytes. J. Electrochem. Soc. 1987, 134, 1524-1535.

42. Bhattacharyya, A.J.; Maier, J. Second phase effects on the conductivity of non-aqueous salt solutions: "Soggy Sand Electrolytes". Adv. Mater. 2004, 16, 811-814.

43. Capiglia, C.; Mustarelli, P.; Quartarone, E.; Tomasi, C.; Magistris, A. Effects of nanoscale $\mathrm{SiO}_{2}$ on the thermal and transport properties of solvent-free, poly(ethylene oxide) (PEO)-based polymer electrolytes. Solid State Ionics 1999, 118, 73-79.

44. Grande, L.; Paillard, E.; Kim, G.-T.; Monaco, S.; Passerini, S. Ionic liquid electrolytes for Li-air batteries: Lithium metal cycling. Int. J. Mol. Sci. 2014, 15, 8122-8137.

45. Bard, A.J.; Faulkner, L.R. Electrochemical Methods Fundamentals and Applications; Wiley and Son: New York, NY, USA, 2001. 
46. Appetecchi, G.B.; Scaccia, S.; Tizzani, C.; Alessandrini, F.; Passerini, S. Synthesis of hydrophobic ionic liquids for electrochemical applications J. Electrochem. Soc. 2006, 153, A1685-A1691.

47. Appetecchi, G.B.; Montanino, M.; Zane, D.; Carewska, M.; Alessandrini, F.; Passerini, S. Effect of the alkyl group on the synthesis and the electrochemical properties of $N$-alkyl- $N$-methylpyrrolidinium bis(trifluoromethanesulfonyl)imide ionic liquids. Electrochim. Acta 2009, 54, $1325-1332$.

48. MacMullin, R.B.; Muccini, G.A. Characteristics of porous beds and structures. AIChE J. 1956, 2 , 393-403.

(C) 2014 by the authors; licensee MDPI, Basel, Switzerland. This article is an open access article distributed under the terms and conditions of the Creative Commons Attribution license (http://creativecommons.org/licenses/by/3.0/). 